NBER WORKING PAPER SERIES

\title{
SOCIAL SECURITY PROGRAMS AND \\ RETIREMENT AROUND THE WORLD: MICRO ESTIMATION
}

\author{
Jonathan Gruber \\ David A. Wise \\ Working Paper 9407 \\ http://www.nber.org/papers/w9407
}
NATIONAL BUREAU OF ECONOMIC RESEARCH
1050 Massachusetts Avenue
Cambridge, MA 02138
December 2002

\section{Introduction and Summary of papers by:}

A. Dellis, R. Desmet, A. Jousten, and S. Perelman, Belgium

M. Baker, J. Gruber, K. Milligan, Canada

P. Bingley, N.D. Gupta, and P.J. Pedersen, Denmark

D. Blanchet and R. Mahieu, France

A. Börsch-Supan, S. Kohnz, and R. Schnabel, Germany

A. Brugiavini and F. Peracchi, Italy

T. Oshio, A Oishi, and N. Yashiro, Japan

M. Boldrin, S. Jimenez-Martin, and F. Peracchi, Spain

M. Palme and I. Svensson, Sweden

R. Blundell, C. Meghir, and S. Smith, United Kingdom

C. Coile and J. Gruber, United States

The views expressed herein are those of the authors and not necessarily those of the National Bureau of Economic Research.

(C) 2002 by Jonathan Gruber and David A. Wise. All rights reserved. Short sections of text not to exceed two paragraphs, may be quoted without explicit permission provided that full credit including, (C) notice, is given to the source. 
Social Security Programs and Retirement Around the World: Micro Estimation Jonathan Gruber and David A. Wise

NBER Working Paper No. 9407

December 2002

\begin{abstract}
This is the introduction to and summary of the second stage of a international research project to study the relationship between social security provisions and retirement. The project relies on the analyses of a large group of economists in 12 countries who conduct the analysis for each of their countries. In the first stage we documented the enormous disincentives for continued work at older ages in many countries. The introduction to the first volume from the project concluded with a striking graph showing a strong relationship across countries between social security program incentives to retire and the proportion of older persons out of the labor force.
\end{abstract}

The results in this volume show the large magnitude of these effects. Across 12 countries with very different social security programs and labor market institutions, the results consistently show that program incentives accord strongly with retirement decisions. The magnitude is illustrated by the simulations reported in each country paper. Considering the average across all countries, a reform that delays benefit eligibility by three years would likely reduce the proportion of men 56 to 65 out of the labor force between 23 and 36 percent, perhaps closer to 36 percent in the long run.

On the other hand, an illustrative "common reform"-- with early retirement at age 60, normal retirement age 65 , and actuarial reduction in benefits between 65 and 60--has very disparate effects across the countries, depending on the provisions of the current program in each country. There is a strong correspondence between the simulation results and a priori expectations.

The results leave little doubt that social security incentives have a strong effect on retirement decisions. And the estimates show that the effect is similar in countries with very different cultural histories, labor market institutions, and other social characteristics. While countries may differ in many respects, the employees in all countries react similarly to social security retirement incentives. The simulated effects of illustrative reforms reported in the country papers make clear that changes in the provisions of social security programs would have very large effects on the labor force participation of older employees.

Jonathan Gruber

Department of Economics

MIT, E52-355

Cambridge, MA 02142-1347

and NBER

gruberj@mit.edu
David A. Wise

National Bureau of Economic Research

1050 Massachusetts Avenue

Cambridge, MA 02135

dwise@nber.org 


\title{
SOCIAL SECURITY PROGRAMS AND RETIREMENT AROUND THE WORLD: MICRO ESTIMATION
}

\author{
INTRODUCTION AND SUMMARY \\ by \\ Jonathon Gruber and David A. Wise
}

\begin{abstract}
If they aren't paid, people don't work. This fundamental economic principle is dramatically demonstrated by social security provisions and retirement. The social security programs in most developed countries are financed on a pay-as-you-go basis. Under this arrangement, most countries have accumulated large unfunded liabilities and in many countries face looming financial burdens. The aging of the populations in almost all countries is often cited as the reason for the financial burdens faced by the social security programs. Many of the programs are very generous and thus are increasingly costly as the population ages-with a greater proportion of the population retired and collecting benefits, relative to the fraction of the population in the labor force and paying for the benefits. Perhaps just as important, although not as widely appreciated, is that the provisions of the programs themselves typically encourage retirement by reducing pay for work. This penalty on work induces older employees to leave the labor force early and thus magnifies the financial burden caused by population aging.
\end{abstract}

This volume represents the second stage of a research project to study the relationship between social security provisions and retirement. The first stage of the project is reported in Gruber and Wise (1999a, 1999b). In that volume, we documented the enormous disincentives for continued work at older ages in many countries. The analysis also revealed a strong correspondence across countries between social security program incentives to retire early and the proportion of older persons that has left the labor force. The weight of the evidence suggested that this relationship was largely causal. The results of the second phase strongly affirm the causal relationship between retirement and social security incentives to quit work.

In this second stage, we turn to country-by-country analysis of retirement behavior based on micro data. The research teams in each of 12 countries, compiled comprehensive large data bases of individuals. The data in each country match 
information on retirement decisions to the retirement incentives inherent in the social security provisions of each country. Retirement models were estimated, based on the micro data. The results show the enormous effect of social security incentives on retirement. And, the uniformity of findings is striking. In every country, the quantitative magnitude of the program incentive effects on retirement is very large.

The key advantage of this micro estimation approach is that in each country the effects on retirement of changes in social security provisions can be predicted. To demonstrate the effect of such changes, the country papers in this volume include simulations of the effects of two illustrative reforms: One illustrative reform delays the benefit eligibility ages in each in each country. A second illustrative reform assumes common provisions in each of the countries--reducing retirement incentives in some countries and increasing incentives in other countries. Under the first reform, the simulations show a large reduction in retirement in each country, and a corresponding increase in the labor force participation of older workers in each country. Under the second reform, the simulations show an increase in retirement in some countries and a decrease in other countries, in accordance with the relationship between the current country provisions and the common reform provisions.

In short: the findings confirm the conclusions based on the first stage of this ongoing project, and, in addition, illustrate the enormous magnitude of the effect that changes in social security provisions would have on retirement and thus the labor force participation of older people.

Like the first stage, this second stage of the project relies on the analyses of a large group of economists who conduct the analysis for each of their countries. The authors of the individual country papers in this volume are:

$\begin{array}{ll}\text { Belgium } & \text { A. Dellis, R. Desmet, A. Jousten, and S. Perelman } \\ \text { Canada } & \text { Michael Baker, Jonathan Gruber, Kevin Milligan } \\ \text { Denmark } & \text { Paul Bingley, Nabanita Datta Gupta, and Peder J. Pedersen } \\ \text { France } & \text { Didier Blanchet and Ronan Mahieu } \\ \text { Germany } & \text { Axel Börsch-Supan, Simone Kohnz, and Reinhold Schnabel } \\ \text { Italy } & \text { Agar Brugiavini and Franco Peracchi } \\ \text { Japan } & \text { Takashi Oshio, Akiko Oishi, and Naohiro Yashiro } \\ \text { Netherlands } & \text { Arie Kapteyn and Klaas de Vos } \\ \text { Spain } & \text { Michele Boldrin Sergi Jimenez-Martin, and Franco Peracchi } \\ \text { Sweden } & \text { Mårten Palme and Ingemar Svensson } \\ \text { United Kingdom } & \text { Richard Blundell, Costas Meghir, and Sara Smith } \\ \text { United States } & \text { Courtney Coile and Jonathan Gruber }\end{array}$

The central feature of the project is the presentation of comparable analysis in each of the countries. Each of the country studies follows essentially the same format, although country-specific issues important for a given country are often discussed as part of the analysis done for that country. 


\section{A. BACKGROUND: THE FIRST STAGE}

The goal of the first stage of the project was to describe the incentives inherent in the social security provisions in the project countries and to relate the incentives to the labor force participation of older workers. Each of the studies in the first volume begins with a description of the historical evolution of labor force participation and then presents data on the current age-specific activities and income sources of men and women. Each of the papers presents data for men and women on: (1) Labor force participation rates by age interval between 1960 and the present. (2) The proportion of employees covered by the public pension system and the proportion of persons over 55 receiving public pensions, from 1960 to the present. (3) Replacement rates under the public pension system from 1960 to the present. (4) Current labor force participation rates by age. (5) Labor force status - employed, unemployed, disability, retired. (5) Proportion receiving various public "pensions" -- e.g. old age, disability, survivor - by age. (6) Proportions receiving employer-provided pensions, by age. (7) Source of household income by age. (8) Retirement and public pension hazard rates by age. Each paper then describes the institutional features of the country's social security system, highlighting any interactions with other public and private programs that might also influence retirement behavior. The core of each paper is a detailed analysis of the retirement incentives inherent in the provisions of that country's retirement income system. By making the same analytic calculations and by presenting the same simulations in each of the countries, the individual studies provide a means of comparing the retirement incentives among the countries.

Because it provides the background and the motivation for the continuing project, we summarize here the key results from the first stage of the project. The decline in the labor force participation of older persons is perhaps the most dramatic feature of labor force change over the past several decades. The decline has been striking in all but one of the countries studied here. The labor force participation rates of men aged 60 to 64 for the years 1960 to 1996 are shown for each of the eleven countries in Figure 1, which for ease of exposition is presented in two panels. (Denmark was added to the project after the first stage was completed.) The decline was substantial in each of the countries, but was much greater in some countries than in others. In the early 1960s, the participation rates were above $70 \%$ in each of the countries and above $80 \%$ in several countries. By the mid 1990s, the rate had fallen to below $20 \%$ in Belgium, Italy, France, and the Netherlands. It had fallen to about $35 \%$ in Germany and $40 \%$ in Spain. Although United States analysts have often emphasized the "dramatic" fall in that country, the U.S. decline from $82 \%$ to $53 \%$ was modest in comparison to the much more precipitous decline in these European countries. The decline to $57 \%$ in Sweden was also large, but modest when compared to the fall in other countries. Japan stands out with the smallest decline of all the countries, from about $83 \%$ to $75 \%$. Each of the country papers presents completely parallel labor force and other data for men and women, including current labor force participation and labor force departure rates by age, which are key components of the analysis in this volume.

Page 3 
By considering the labor force participation rates by age in each country it is possible to calculate the proportion of person in a given age interval who were out of the labor force. These "unused productive capacity" measures for all of the countries are shown in Figure 2, for men in the age range 55 to 65 . For the entire age range from 55 to 65 , unused capacity ranges from 67 percent in Belgium to 22 percent in Japan. The goal was then to consider how this measure of labor force participation was related to the provisions of the social security programs in the countries.

The incentive measure calculated in this first volume was the implicit social security tax on work. To understand that measure it is useful to think of wage compensation for working an additional year in two components. The first is wage earnings. The second component is the "increase" in the expected present discounted value of promised future social security benefits, know as the accrual in Social Security Wealth $(S S W)=S S W_{t+1}-S S W_{t}$. It is natural to think of this difference as positive, or at least not negative. That is, if a person works for an additional year and thus forgoes one year of benefits, it might be expected that benefits begun one year later would be increased enough to offset the fact that they are received for one fewer years. This is true, for example, for the typical worker in the United States: if a worker forgoes claiming benefits at the earliest possible age (62) and works another year, subsequent benefits are increased by 6.67 percent to account for the fact that benefits will be received for one fewer years.

In most of the countries studied in this project, however, the accrual is significantly negative. This is a consequence in large part of not increasing benefits enough if the age of benefit receipt is delayed--benefits are not "actuarially fair." Thus what the worker gains in wage earnings is partially, or even largely, offset by a loss in future social security benefits. We call the ratio of this loss to wage earnings (after tax) the social security implicit tax on earnings. In many countries this tax can be 80 percent or more at certain ages. Suppose that the tax rates for each of the years from the early retirement to age 69 are summed. We call this the tax force to retire. It is shown for all the countries in Figure 3.

The relationship between the (logarithm of the) tax force to retire and the proportion of men age 55 to 65 that is out of the labor force (unused capacity) is shown in Figure 4. There is a striking correspondence between the two series, showing a clear relationship between the social security tax on work and departure from the labor force. A number of examples in the previous volume, some of which are replicated below, suggest that the relationship is largely causal. We concluded in the introduction to that volume that:

It is clear that there is a strong correspondence between the age at which benefits are available and departure from the labor force. Social security programs often provide generous retirement benefits at young ages. In addition, the provisions of these programs often imply large financial penalties on labor earnings beyond the social security early retirement age. Furthermore, in many 
countries disability and unemployment programs effectively provide early retirement benefits before the official social security early retirement age. We conclude that social security program provisions have indeed contributed to the decline in the labor force participation of older persons, substantially reducing the potential productive capacity of the labor force. It seems evident that if the trend to early retirement is to be reversed, as will almost surely be dictated by demographic trends, changing the provisions of social security programs that induce early retirement will play a key role.

\section{B. THE SECOND STAGE ANALYSIS AND ISSUES}

The first stage of this project established two key results: (1) that the social security systems in many countries provide enormous incentives to leave the labor force at older ages; and (2) that there is a strong correspondence between social security incentives to retire and the withdrawal of older workers from the labor force. The implication is that social security incentives to retire are likely an important cause of the low labor force participation of older workers in many countries. The relationships in the first volume, however, do not provide a means of estimating the magnitude of the effect on labor force participation of changes in plan provisions.

Thus, in this second stage of the project, we undertake analysis to estimate how much the retirement age would change if social security provisions were changed, based on within-country analysis of the determinants of retirement. The analysis is based on the micro data within each country, considering the relationship between retirement and the incentives faced by individual employees. That is, rather than considering system-wide incentives for representative persons (such as those with median earning histories), and comparing these incentives with aggregate labor force participation across countries, we now turn to micro-econometric analyses within countries. The results of these analyses are based on differences in individual circumstances within a given country.

This approach has two key advantages. First, the analyses in this volume show that social security retirement incentives have very similar effects on labor force participation in all countries. In particular, the results strongly confirm that the relationship between labor force participation and retirement across countries is not the result of cultural differences among countries, that could yield different norms, or "taste" for work, at older ages. That is, the within country analyses show similar responses to retirement incentive effects, even though the counties differ with respect to cultural histories and institutions.

Second, the analysis of micro data also allows consideration of several feature of social security systems, as well as individual attributes, that may simultaneously affect retirement decisions. In particular, we can consider jointly the age at which benefits are first available and the incentive to retire once benefits are available. Both of these 
features were shown in the first stage of the project to be important determinants of retirement.

The importance of benefit eligibility ages presents a particular challenge for the analyses in this volume. We believe that much of the impact of social security provisions is likely to be through the choice of benefit eligibility ages, which in some instances may tend to establish social norms for retirement. For example, a common finding of many of the analyses in this volume is that even very detailed models of retirement incentives cannot explain the large jumps in retirement rates at normal and early entitlement ages. As a result, the retirement effects of major system reforms (like raising the early entitlement age) may be greatly understated by comparisons among individuals within a given retirement income system, who all face the same eligibility ages. In addition, small private saving may limit the option of most persons to retire before pension benefits are available (many people are "liquidity constrained"), and such effects may not be captured by retirement models. We discuss below how we deal with this critical issue.

In addition, as emphasized in the first volume, unemployment and disability benefits often provide early retirement income before the nominal social security normal retirement age. Thus in many countries, to estimate the effect of the plan provisions on retirement, it is necessary to consider all three programs jointly, which is done in the micro-econometric analyses in this volume .

Considered jointly, we believe that the analyses in this volume provide overwhelmingly confirmation that the provisions of social security programs play a key role in the determination of retirement decisions. This result complements the conclusion from the first stage of the analysis. In addition, the estimates in this volume allow prediction of the effects on retirement of changes in program provisions-and the effect of changes on program costs, which will be taken up in the next stage of the project.

As in the first volume, the analysis in each country is follows a template, so that results can be compared across countries. The micro analysis in each country is based on a sample of individuals. In some cases, the data come largely from administrative records. In other cases, the data were obtained from special surveys. The coverage is not precisely the same in each country. For example, the data for Italy pertain to private sector workers only, excluding public sector employees. Nonetheless, it has been possible to estimate the same models in each country, even though the population covered by the country data sets may differ in some respects.

In this section B, we first describe the "incentive measures" used in the analysis, as well as other features of the model specifications. The alternative incentive measures are constructed economic variables that describe the financial gain or loss from continuing to work. Then we discuss the method used to obtain estimates when there are multiple routes to retirement. Next we briefly summarize the parameter 
estimates obtained in the analyses across the 12 countries.

In the section $\mathrm{C}$, we discuss a key empirical regularity that strongly influences the analyses undertaken in this volume: the correspondence between benefit eligibility ages and retirement decisions.

In section $\mathrm{D}$. we describe the simulations undertaken to summarize the implications of the estimated models, and discuss the simulation results.

The simulations describe the effect of illustrative "policy changes." The goal is to provide an understanding of the nature of the findings, focusing on selected portions of the analyses described in detail in the country papers. The simulations demonstrate the implications of the retirement model estimates.

As part of this discussion, we take some care to explain the different methods of simulation that are used in the analysis and why certain features of the simulation methods are of key importance. A central aspect of the analysis is experimentation with various approaches to estimation, and to simulations based on the estimates. The aim is to determine the most reliable methods to use in the subsequent stages of the project.

Some of the discussion is necessarily somewhat technical. We believe, however, that it is important to present an overview of the critical features of the analysis so that readers can approach the individual country papers with a broad understanding of the issues and rational behind the approach taken in the country analyses. Thus in the text of this introduction we have explained the main features of the analysis and have included some additional more technical detail in an appendix.

\section{The Estimation Models: Incentive Measures and Control Variables}

The goal of the analysis in the country papers is to estimate the probability of retirement, based on the provisions of the country social security systems-which provide differential incentives depending on individual employee circumstances--and on other individual attributes of employees. The focus of the analysis is the plan provisions. In particular, how the incentives to retire, inherent in plan provisions, are in fact related to the retirement choices that individuals make. There are several ways that the incentives might be measured. All of the measures describe the financial gain or loss from continuing work. The specifications used in the country papers are summarized in the table below. The most important variable in each specification is the "incentive measure," which is noted across the top of the table. In addition to these measures, the models control for various other variables (covariates).

The specifications are summarized in Table 1 below. Each of the specifications includes social security wealth (SSW). The expectation is that, all else equal, persons with greater social security wealth are more likely to retire. In principle, total wealth should be controlled for, but in most countries the data do not provide measures of 
other forms of wealth.

\begin{tabular}{|l|c|c|c|c|c|c|}
\hline \multirow{2}{*}{ Table 1. Estimation Method (Incentive Measure) and Variables } \\
\hline \multirow{2}{*}{ Variables } & \multicolumn{3}{|c|}{ Estimation Method (Incentive Measure) } \\
\cline { 2 - 8 } & \multicolumn{2}{|c|}{$\begin{array}{c}\text { Single Year } \\
\text { Accrual }\end{array}$} & \multicolumn{2}{c|}{ Peak Value } & \multicolumn{2}{c|}{ Option Value } \\
\hline Social security wealth (SSW) & $\mathrm{X}$ & $\mathrm{X}$ & $\mathrm{X}$ & $\mathrm{X}$ & $\mathrm{X}$ & $\mathrm{X}$ \\
\hline Linear age & $\mathrm{X}$ & -- & $\mathrm{X}$ & -- & $\mathrm{X}$ & - \\
\hline Individual age indicators & -- & $\mathrm{X}$ & -- & $\mathrm{X}$ & -- & $\mathrm{X}$ \\
\hline Earnings & $\mathrm{X}$ & $\mathrm{X}$ & $\mathrm{X}$ & $\mathrm{X}$ & $\mathrm{X}$ & $\mathrm{X}$ \\
\hline Sector & $\mathrm{X}$ & $\mathrm{X}$ & $\mathrm{X}$ & $\mathrm{X}$ & $\mathrm{X}$ & $\mathrm{X}$ \\
\hline Demographics & $\mathrm{X}$ & $\mathrm{X}$ & $\mathrm{X}$ & $\mathrm{X}$ & $\mathrm{X}$ & $\mathrm{X}$ \\
\hline
\end{tabular}

The focus of the analysis is on forward-looking measures of the incentive for retirement, or for continued work. A natural starting point is a measure that looks ahead only one year, the single year accrual measure. This measure captures the effect of another year of work on future benefits. Thus, as a base for comparison the country analyses present the single-year accrual incentive measure.

However, it has been shown in other contexts, ${ }^{1}$ as well as in the first volume of this project, that the financial gain from continuing to work may vary from year to year. That is, the gain from working one more year may be large, for example, but once that single additional year is worked, the gain from working one more year may be small, or even negative. Likewise, the gain from one more year may be small, but might then be followed by a year of large gain. In this case, a person who decides to retire based on looking forward just one year, would forego the gain in pension wealth that would be gained by continuing to work for two years. Thus a key principle of the approach followed here is that the estimation should account for the pension accrual not just in the next year, but many years into the future.

The benchmark approach for considering the entire future path of accruals is the "option value" model. ${ }^{2}$ To summarize, this model evaluates the expected present

'See for example, Lazear (1983), Kotlikoff and Wise (1985,1989), Coile and Gruber (2000a).

${ }^{2}$ See Stock and Wise (1990a, 1990b). 
discounted value of incomes for all possible future retirement ages, and then measures the "value" of retirement today versus the value at the optimal date (perhaps today but more likely in the future). If looking ahead suggests gains from work at some time in the future, there is an incentive for the person to remain in the labor force to take advantage of these gains.

The relationship between the measures can be explained briefly. As described above, the social security accrual from one year to the next is given by

$$
S S W_{t+1}-S S W_{t}
$$

That is, this measure describes the change in promised future social security benefits from working one additional year.

A simplified version of the option value measure at age $t$ can be described by:

$$
\begin{aligned}
& \text { Simplified } " \mathrm{OV}_{t}\left(r^{*}\right) \\
& =\left(\begin{array}{l}
\text { discounted } \\
\text { future wages } \\
\text { through age } r *
\end{array}\right)+\left[\left(\begin{array}{l}
\text { discounted } \\
\text { benefits if } \\
\text { retire at } r *
\end{array}\right)-\left(\begin{array}{l}
\text { discounted } \\
\text { benefits if } \\
\text { retiree at } t
\end{array}\right)\right]
\end{aligned}
$$

$$
=\left(\begin{array}{l}
\text { discounted } \\
\text { future wages } \\
\text { through age } r^{*}
\end{array}\right)+[\text { Peak Value }]
$$

In this formulation, a person considering whether to retire at age $t$ considers the present value of benefits if he retires now (at age $t$ ), with the benefits if he retires at some later time. If the person retires at some later age he will gain from future wage earnings, and from any gain in future pension benefits. The gain in wage earnings is represented by the first bracket and the gain in pension benefits by the difference between the terms in the second bracket. The age at which the total of the two components is the greatest is denoted by $\mathrm{r}^{*}$. The option value prescription is that the person will continue to work if this option value is positive. 
Notice that the option value approach as set out above combines both of the components of compensation from working: one component is wage earnings, the other is the change in promised future social security benefits. We label this second component the "peak value". ${ }^{3}$ It includes only social security benefits, and not wage earnings. The peak value occurs at the age that gives the greatest discounted value of social security benefit. That age need not be at $r^{*}$, although for simplicity the two are assumed to be the same in this description. A more precise discussion of the differences in the measures is presented in the appendix.

As emphasized above, a crucial issue in the analyses in this volume is identification-that is, determination of the separate effect of each variable on retirement, as distinct from each of the other variables. A key goal is to determine the effect of plan incentives on retirement. But other individual attributes also influence the decision to retire. For example, persons are more likely to prefer retirement to work as they age. A linear age variable will potentially capture this effect, but only if preferences for leisure evolve linearly with age. Individual wage differences may also proxy for differences in the preference for work versus retirement. A wage earning covariate may help to control for this form of heterogeneity among individuals. But both age and wage earnings also determine in part the value of the incentive measures. Thus including age and wage covariates may make it more difficult to accurately determine the effect of the incentive measures-or to accurately isolate the program incentive effects from the effect of worker heterogeneity. To put it another way: the importance of controlling for differences in "taste" for work may suggest the inclusion of the wage and age variables, separate from their incorporation in the option value. But there is a countervailing consideration. Much of the estimated effect of these variables is likely to reflect the influence of financial incentives and not individual heterogeneity. Thus the full effect of the program incentives may be understated when the separate age and earnings controls are included.

The issue of identification also arises in considering the option value as compared with the peak value incentive measures. If individual heterogeneity were not a concern, the option value measure would be the most parsimonious incentive measure to use, as it captures the full financial incentive on retirement of both future wage earnings and retirement benefits combined. But, to the extent that wages proxy for the taste for work, the option value variation across individuals may reflect in part this wage proxy for heterogeneity, rather than the financial retirement incentive. The peak value measure recognizes this possibility by measuring the retirement incentive by the future stream of retirement benefits only, without including the future stream of wage earnings. But to the extent that future wage earnings have an important incentive influence on retirement, the peak value approach understates the full effect of financial incentives on retirement.

${ }^{3}$ As proposed by Coile and Gruber (2000a, 2000b). 
Perhaps the most important identification issue arises when age-specific variables are included to estimate the retirement effect of program eligibility ages. It is common to find that the retirement rate at certain ages is larger (or smaller) than would be predicted on the basis of an incentive measure alone. For example, in the United States the retirement rate at 65 is noticeably higher than is predicted based on financial incentives alone. Perhaps this is due to a "customary retirement age" effect. Since age 65 is the normal retirement age, many employees may think that age 65 is "the age to retire." In addition, in virtually no instance in any country do employees typically retire before some form of retirement benefits are available. The retirement rate at the early retirement age-the age at which a person is first eligible for benefits--is typically substantially greater than would be predicted on the basis of financial measures alone. This empirical regularity likely reflects a "liquidity constraint"; most employees have not saved enough to retire without receiving public social security or employer-provided pension benefits. To capture this effect, some of the specifications allow an indicator variable for each age. These indicator variables allow retirement to jump or decline at each age, after controlling for the financial incentive measures. But the inclusion of these age indicator variables in particular raises the identification question: here the issue is whether the effect of the financial incentive measures can be distinguished from the effect on retirement of plan eligibility ages. This is a critical issue and is discussed in more detail below.

There is no "right answer" to these identification dilemmas. The country analyses in this volume follow what is perhaps a conservative as well as a flexible approach. All of the specifications control for background variables, including sex, education, industry of employment, and both current and average lifetime earnings. This is the conservative part. The flexibility is reflected in the different incentive measure specifications, each estimated using linear age and then again using indicator variables for each age. In this way the sensitivity of the findings to different incentive measures and to the controls that are included in the analysis can be assessed.

One additional note on estimation: The option value model as set out by Stock and Wise, and in several subsequent applications, was estimated by maximum likelihood methods to obtain the relevant behavioral parameters. In this cross-country context, however, we concluded that that approach would likely pose numerical complexities that would best be avoided for this comparative analysis over a large number of countries. Thus the estimation undertaken in the papers in this volume is typically based on a regression counterpart to the option value model, as well as two other approaches, as explained above. In some countries, however, the option value parameters in the Stock and Wise specification have been estimated by a grid search, and in other instances the Stock and Wise option value parameter estimates have been used to calculate the option value that is used in the regression. In at least one country, the option value model was estimated by maximum likelihood.

\section{Multiple retirement options}


In some countries, like the United States, social security is the single public program that provides retirement benefits to the vast majority of retirees. The only retirement decision is then at what age to choose to retire under this program. (A small fraction of persons retire under the public disability program and many employees are covered by employer-provided pension plans.) In other countries, however, there are two or more programs under witch a person can retire. Germany is a good example.

Figure 5 shows paths to retirement for men in Germany between 1960 and 1995. The figure shows clearly the changes in the pathways to retirement after the 1972 reform, discussed below. Here, we draw attention to the multiple paths to retirement. All persons are eligible to retire at age 65 , the social security program normal retirement age. But only a small proportion of employees work until that age. A large fraction of employees retires under the disability program before age 60 . Others retire under the social security disability program available after age 60 . Some can retire under the social security system unemployment program after age 60 . Still others are eligible to retire at age 63 under the "flexible" retirement program that allows persons with long service to retire at that age-essentially the early retirement age. In addition to these programs, liberal interpretation of unemployment plan provisions allows persons to retire with unemployment benefits before age 60 . Whether a given person is eligible for a program depends on specific plan provisions, like eligibility for flexible retirement at age 63. Eligibility for other programs, like disability or unemployment, is uncertain.

In Germany, the approach is to assign (predict) eligibility probabilities for each of the programs at each age, depending on the empirical probabilities of retirement under each of the programs at that age. Then the incentive measures are weighted averages, with the weights given by the probabilities. This instrumental variable method is described in more detail in the appendix, using the situation in Denmark as an example.

\section{Parameter Estimates}

We do not attempt in this introduction to provide a detailed discussion of the estimates. Rather, we rely on the simulations based on the parameter estimates to indicate the implications of the estimated models. The simulations are discussed below. Here we highlight the striking common finding in virtually all the country papers: the retirement incentives inherent in most social security programs are strongly related to early retirement.

The estimation results are summarized in Table 2 below. For each incentive specification, the table shows the sign and the statistical significance (at the five percent level denoted by "*”) of the estimated effect of the incentive measure. The table also shows the sign and the statistical significance of social security wealth. For each incentive measure, the sign and significance level are shown when linear age is used and when the age-specific indicator variables are used. 


\begin{tabular}{|c|c|c|c|c|c|c|}
\hline \multirow{3}{*}{ Country } & \multicolumn{6}{|c|}{ Estimation Method (Incentive Measure) } \\
\hline & \multicolumn{2}{|c|}{ Single Year Accrual } & \multicolumn{2}{|c|}{ Peak Value } & \multicolumn{2}{|c|}{ Option Value } \\
\hline & $\begin{array}{l}\text { Linear } \\
\text { Age }\end{array}$ & $\begin{array}{c}\text { Age } \\
\text { Indicators }\end{array}$ & $\begin{array}{l}\text { Linear } \\
\text { Age }\end{array}$ & $\begin{array}{c}\text { Age } \\
\text { Indicators }\end{array}$ & $\begin{array}{l}\text { Linear } \\
\text { Age }\end{array}$ & $\begin{array}{c}\text { Age } \\
\text { Indicators }\end{array}$ \\
\hline Belgium & $\begin{array}{l}\text { acc:-* } \\
\text { ssw:-* }\end{array}$ & $\begin{array}{l}\text { acc:-* } \\
\text { ssw:-* }\end{array}$ & $\begin{array}{l}\text { pv:-* } \\
\text { ssw-*: }\end{array}$ & $\begin{array}{l}\text { pv:-* } \\
\text { ssw:-* }\end{array}$ & $\begin{array}{l}\text { ov:-* } \\
\text { ssw:- }\end{array}$ & $\begin{array}{l}\text { OV:-* } \\
\text { Ssw:- }\end{array}$ \\
\hline Canada & $\begin{array}{l}\text { acc: :* } \\
\text { ssw: }{ }^{*}\end{array}$ & $\begin{array}{l}\text { acc: } \text {-* }^{*} \\
\text { ssw: }{ }^{*}\end{array}$ & $\begin{array}{l}\text { pv: } \text {-* }^{*} \\
\text { ssw: }+^{*}\end{array}$ & $\begin{array}{l}\text { pv: } \text {-* }^{*} \\
\text { ssw: }{ }^{*}\end{array}$ & $\begin{array}{l}\text { ov:-*} \\
\text { Ssw:+* }\end{array}$ & $\begin{array}{l}\text { OV: } \text {-* }^{*} \\
\text { SSW:+* }\end{array}$ \\
\hline Denmark & $\begin{array}{l}\text { acc: }+^{*} \\
\text { ssw: }+^{*}\end{array}$ & $\begin{array}{l}\text { acc: -* } \\
\text { ssw:+ }\end{array}$ & $\begin{array}{l}\text { pv: } \text {-* }^{*} \\
\text { ssw: }+^{*}\end{array}$ & $\begin{array}{l}\text { pv: } \text {-* }^{*} \\
\text { ssw: }{ }^{*}\end{array}$ & $\begin{array}{l}\text { ov: } \text {-* }^{*} \\
\text { SsW:+* }\end{array}$ & $\begin{array}{l}\text { OV: -* } \\
\text { SSW:+* }\end{array}$ \\
\hline France & $\begin{array}{l}\text { acc: :* } \\
\text { ssw:-* }\end{array}$ & $\begin{array}{l}\text { acc: :* } \\
\text { ssw:-* }\end{array}$ & $\begin{array}{l}\text { pv: } \text {-* }^{*} \\
\text { ssw:-* }\end{array}$ & $\begin{array}{l}\text { pv: -* } \\
\text { ssw:- }\end{array}$ & $\begin{array}{l}\text { OV: -* } \\
\text { SSW:-* }\end{array}$ & $\begin{array}{l}\text { OV: :* } \\
\text { SSW:-* }\end{array}$ \\
\hline Germany & $\begin{array}{l}\text { acc: -* } \\
\text { ssw:- }\end{array}$ & $\begin{array}{l}\text { acc:-* } \\
\text { ssw:- }\end{array}$ & $\begin{array}{l}\text { pv:-* } \\
\text { ssw:- }\end{array}$ & $\begin{array}{l}\text { pv:-* } \\
\text { ssw:- }\end{array}$ & $\begin{array}{l}\text { ov:-* } \\
\text { ssw:- }\end{array}$ & $\begin{array}{l}\text { OV: -* } \\
\text { SSW:-* }\end{array}$ \\
\hline Italy & $\begin{array}{l}\text { acc: -* } \\
\text { ssw:-* }\end{array}$ & $\begin{array}{l}\text { acc: -* } \\
\text { ssw:- }\end{array}$ & $\begin{array}{l}\text { pv: + } \\
\text { ssw:+ }\end{array}$ & $\begin{array}{l}\text { pv: - } \\
\text { ssw:- }\end{array}$ & $\begin{array}{l}\text { ov: + } \\
\text { ssw:+ }\end{array}$ & $\begin{array}{l}\text { ov: - } \\
\text { ssw:+ }\end{array}$ \\
\hline Japan & $\begin{array}{l}\text { acc: -* } \\
\text { ssw:+ }\end{array}$ & $\begin{array}{l}\text { acc: -* } \\
\text { ssw:- }\end{array}$ & $\begin{array}{l}\text { pv: -* } \\
\text { ssw:- }\end{array}$ & $\begin{array}{l}\text { pv: -* } \\
\text { ssw:- }\end{array}$ & $\begin{array}{l}\text { ov: -* } \\
\text { Ssw:+ }\end{array}$ & $\begin{array}{l}\text { ov: + } \\
\text { ssw:- }\end{array}$ \\
\hline Neth. & $\begin{array}{l}\text { acc: }+^{*} \\
\text { ssw: }+^{*}\end{array}$ & $\begin{array}{l}\text { acc: }+^{*} \\
\text { ssw: }+\end{array}$ & $\begin{array}{l}\text { pv: } \text {-* }^{*} \\
\text { ssw: }{ }^{*}\end{array}$ & $\begin{array}{l}\text { pv: } \text {-* }^{*} \\
\text { ssw: }{ }^{*}\end{array}$ & $\begin{array}{l}\text { ov: } \text {-* }^{*} \\
\text { SSW:+* }\end{array}$ & $\begin{array}{l}\text { OV: -* } \\
\text { SSW:+* }\end{array}$ \\
\hline Spain & $\begin{array}{l}\text { acc: -* } \\
\text { Ssw: }+^{*}\end{array}$ & $\begin{array}{l}\text { acc: }+ \\
\text { ssw: }{ }^{*}\end{array}$ & $\begin{array}{l}\text { pv: -* } \\
\text { ssw:- }\end{array}$ & $\begin{array}{l}\text { pv: + } \\
\text { ssw:+ }\end{array}$ & $\begin{array}{l}\text { ov: - } \\
\text { ssw:+ }\end{array}$ & $\begin{array}{l}\text { ov: + } \\
\text { ssw:+ }\end{array}$ \\
\hline Sweden & $\begin{array}{l}\text { acc: :* } \\
\text { ssw: }{ }^{*}\end{array}$ & $\begin{array}{l}\text { acc: - } \\
\text { ssw:+* }\end{array}$ & $\begin{array}{l}\text { pv: } \text {-* }^{*} \\
\text { ssw: }+^{*}\end{array}$ & $\begin{array}{l}\text { pv: } \text {-* }^{*} \\
\text { ssw: }{ }^{*}\end{array}$ & $\begin{array}{l}\text { ov: } \text {-* }^{*} \\
\text { SSW:+* }\end{array}$ & $\begin{array}{l}\text { ov: -* } \\
\text { Ssw:+ }\end{array}$ \\
\hline UK & $\begin{array}{l}\text { acc: } \text {-* }^{*} \text { ssw:+* }\end{array}$ & $\begin{array}{l}\text { acc: - } \\
\text { ssw:+* }\end{array}$ & $\begin{array}{l}\text { pv: - } \\
\text { ssw:+* }\end{array}$ & $\begin{array}{l}\text { pv: - } \\
\text { ssw:+* }\end{array}$ & $\begin{array}{l}\text { OV: } \text {-* }^{*} \\
\text { SSW:+* }\end{array}$ & $\begin{array}{l}\text { OV: } \text {-* }^{*} \\
\text { SSW:+* }\end{array}$ \\
\hline US & $\begin{array}{l}\text { acc: }+^{*} \\
\text { ssw: }+^{*}\end{array}$ & $\begin{array}{l}\text { acc: }+ \\
\text { ssw:+ }\end{array}$ & $\begin{array}{l}\text { pv: } \text {-* }^{*} \\
\text { ssw:+* }\end{array}$ & $\begin{array}{l}\text { pv: -* } \\
\text { ssw:+ }\end{array}$ & $\begin{array}{l}\text { ov: -* } \\
\text { Ssw:+ }\end{array}$ & $\begin{array}{l}\text { OV: -* } \\
\text { SSW:-* }\end{array}$ \\
\hline \multicolumn{7}{|c|}{$\begin{array}{l}\text { Note UK: The option valued estimates are significant when standard errors } \\
\text { accounting for repeated observations for the same person are used, and, when } \\
\text { cohort indicator variables, instead of age indicators are used, both the option value } \\
\text { and the peak value incentive measures are very significant. } \\
\text { Note Spain: The indications in this table pertain to the RETA employee group. }\end{array}$} \\
\hline
\end{tabular}


The results in Table 2 are striking. In ten of the twelve countries, almost all of the of the estimated incentive measure effects are negatively related to retirement and significantly different from zero. (With respect to the discussion below, it is also notable that the sign and significance of the incentive measures rarely depends on whether age indicator variables are used in the specification.) In two countries-Italy and Spain-the peak value and option value effects are typically not significant and sometimes of the wrong sign. ${ }^{4}$ Also in these three countries the single year accrual effect is negative and significantly related to retirement in four of the six cases.

The estimated effect of social security wealth (SSW), however, is often not statistically different from zero and in many cases is of the "wrong" sign. In many countries, it is likely easier to identify the effect of the incentive measures than the effect of wealth levels. Because of program provisions, there is much more variation in the incentive measures than in the social security wealth.

Thus, overall, the results from these 12 separate analyses seem to us amazingly consistent. The incentives inherent in retirement income programs are clear determinants of individual retirement behavior. The estimates themselves strongly suggest a causal interpretation of the cross-country results presented in our first volume. The results point to an important relationship between incentive effects and labor force participation, independent of cultural difference among countries. The magnitude of the implied effects are also vary comparable across countries, as shown by the simulations discussed below.

\section{ELIGIBILITY AGES AND RETIREMENT: A KEY EMPIRICAL REGULARITY}

The effect on retirement of the changes in benefit eligibility ages perhaps presents the most difficult prediction challenge of the project. Thus we give special attention to the a consistent empirical regularity in retirement that highlights this challenge. In each country retirement rates are strongly related to specific eligibility ages prescribed in country-specific plan provisions. Perhaps most important is that retirement rates increase sharply at ages of first eligibility for benefits. The age of first eligibility may differ from person to person and varies by program (social security, disability, unemployment, for example) in many countries. In the absence of eligibility for benefits retirement is rare in each of the countries. One way to see this relationship is to consider retirement hazard rates. The hazard rate shows the proportion of persons

${ }^{4}$ In the United Kingdom the option value incentive measures are significant when a "bootstrap" method, that accounts for repeated observations on the same person, is used to calculate standard errors. Also in the United Kingdom, both the peak value and the option value incentive measures are very significant-under conventional standard error estimates--when cohort indicator, instead of age indicator, variables are used. 
employed at a given age who retire over the subsequent year. The empirical regularity between hazard rates and eligibility ages across countries is show in some detail in the first volume of the project. Here, we show additional country examples that help to motivate in particular the simulation and estimation methods used in this volume.

United States: Labor force departure rates for men in the United States are shown in Figure 6 . The hazard rates are close to zero before age 54 and then increase gradually through age 61 . All employees are eligible for social security early retirement benefits at age 62 , and there is a sharp jump in the hazard rate at that age. The rise in departure rates at age 54 can be attributed not to the social security program, but to eligibility for early retirement under employer-provided pension plans.

The importance of eligibility can be seen clearly in Figure 7 . This figure shows hazard rates by pension plan coverage. The hazard rates for men who have no private pension coverage, and are covered only by the social security program are indicated by the line with round markers. The hazard rates for these persons are very close to zero until the social security early retirement age, when they are first eligible for retirement benefits. At that age, there is a sharp increase in the departure rate. The important feature of the pattern is that there is essentially no retirement before that age. ${ }^{5}$

The other line in the figure shows the hazard rates for men who are covered by an employer-provided defined benefit pension plan. The early retirement age under these plans is often age 55 and is rarely over age 60 . The hazard rates are very low before age 55. But for these employees, there is a sharp jump in the hazard rate at age 55 , when many in this group are first eligible for benefits. And then another jump at 62, when social security benefits are first available. If the early retirement age for the United States social security program were raised from 62 to 65 , for example, these data suggest strongly that the jump in the hazard rate at age 62 would no longer occur at that age but would shift to age 65 instead. The critical question is whether the hazard rates would remain close to zero until age 62 .

Germany: The German social security system provides additional and perhaps better examples. Figure 8 is analogous to Figure 6 for the United States and shows hazard rates, with respect to departure from the labor force, for men in Germany. The detailed provisions of the 1972 social security legislation (effective until 1998) are mirrored in the retirement rates by age. In particular, there is a jump in the hazard rate at each important eligibility age. The ages of key plan provisions are also noted on the figure so that the correspondence between provisions and retirement is easily seen. Men who are "disabled" or "unemployed" at age 60 , and have a certain number of years

${ }^{5}$ These rates are based on labor force participation rates of Health and Retirement Study respondents. The precise age of departure from the labor force is obscured by the two-year interval between survey waves, and thus the jump in the hazard rate does not match the age 62 early retirement age exactly. 
of employment under the social security system, are eligible for early retirement at that age. There is a corresponding large jump in the retirement rate at that age. Men who have been employed for 35 years are eligible for early retirement at age 63 and there is a corresponding jump in the retirement rate at that age. The normal retirement age is 65 and all men are eligible for benefits at that age. And, there is a corresponding spike at that age as well. (By age 65, however, fewer than 29 percent of men are still in the labor force in Germany.) In addition, even before age 60, liberal interpretation of disability and unemployment plan provisions effectively serves to provide early retirement benefits, so that many men are eligible for effective early retirement before age 60. There is a corresponding jump in the hazard rates between 55 and 56 .

Like the Unites States data, the German data also suggest that if the eligibility ages were increased, for example, the observed jumps in the hazard rates would also shift upward. This sort of pattern is exhibited in all countries and is shown in detail in the first volume of the project.

The German system provides additional examples that reinforce the importance of specific plan eligibility ages. First, the provisions of the German social security program were changed in 1972, as mentioned above. Second, the provisions for men and women are different. The difference in the pre- and post-reform hazard rates, and the difference in the hazard rates for men and women, highlight the point. Figure 9 shows the distribution of retirement ages for men under the social security system provisions in 1970 and in 1976 . Before the 1972 reform, retirement under the social security program was essentially only possible at the 65 normal retirement age. And there is a corresponding large spike in the distribution at that age. The 1972 reform provided for early ("flexible") retirement at age 63 and in 1976 there is a large concentration of retirement at that age. Notice that retirement at ages before 60 and after 65 was essentially unaffected by the change in plan provisions. The change in hazard rates was essentially confined to the ages affected by the legislation. (These data do not cover retirement under the disability and unemployment programs before age 60. Retirement under these programs, however, is evident in Figure 8 and in Figure 5.)

Figure 10 is like Figure 9, but adds the distribution of retirement ages in 1980. After the 1972 reform, men quickly took up retirement at the 63 early retirement age- as seen in 1976. Over the next few years, retirement through lenient disability and unemployment rules was increasingly taken advantage of, and by 1980 a large retirement concentration at age 60 (through these programs) is evident. Apparently, the ease of retirement at the earlier age was not at first recognized.

In addition, the eligibility ages for men and women differ. The effect of the differences can be seen in Figure 11. This figure shows the distribution of retirement ages, under the social security system, for men and women in 1995. For both men and women there is a concentration of retirement at age 65, the normal retirement age. For both men and women there is also a concentration at age 60, but for different reasons. 
Age 60 is the early retirement age for women. For men, the concentration at age 60 is due to eligibility for disability and unemployment benefits at that age. Women are also eligible for these benefits at age 60, if they have enough years of employment. The key feature of this figure is the retirement behavior at age 63 . For men there is a concentration at age 63, the early ("flexible") retirement age. But this option is not available for women, and there is no concentration at age 63 for women. (Or, few women have enough employment years to retire at that age.)

The United Kingdom: The United Kingdom program also has different provisions for men and women. Men can begin to receive benefits under the public social security program at age 65 . Women can begin to receive benefit at age 60 . These differences are clearly reflected in the retirement patterns of men and women, as shown in Figure 12. This figure shows, the labor force "survival probabilities" for men and women, who do not have an occupational pension. The proportion of women employees still in the labor force drops by about 20 percentage points (from 60 to 40 percent) at age 60 . But there is essentially no decline for men at this age. On the other hand, there is a 20 percentage point drop (from about 40 to about 20 percent) for men at age 65 , when they can receive benefits.

Thus within country differences in labor force departure rates by gender, by pension plan coverage, and over time show clearly that retirement is strongly influenced by eligibility ages. It seems clear that differences in labor force departure rates among countries are also strongly influenced by differences in eligibility ages. We would like the estimation and simulation methods used in the analysis to capture the essence of the empirical regularity between benefit eligibility ages and retirement, and at the same time, capture the effect of the other plan incentive measures as defined above. We give particular attention to this issue below.

\section{SIMULATIONS: METHOD AND RESULTS}

\section{Simulation Method}

Perhaps the best way to judge the implications of the country estimates is to consider the simulations based on the estimates. Thus, the main focus of this introduction is on the two illustrative simulations that are performed for each of the countries. The first simulation predicts the effect of delaying all program benefit eligibility ages by three years. In countries in which disability, unemployment, or other retirement pathways are important, the eligibility age for each of the programs is delayed by three years. The second simulation is intended to predict the effect of the same reform (the "common reform") in each country. Under the common reform, the early retirement age is set at age 60 and the normal retirement age at 65 . Benefits taken before age 65 are reduced "actuarially," by 6 percent for each year before age 65 . Benefits taken after age 65 are increased by 6 percent for each year the receipt of benefits is delayed. In addition, the replacement rate at age 65 is set at 60 percent of 
(projected) age 60 earnings.

The simulations are summarized in the Table 3 below. The country papers show simulations done in nine different ways. For each reform, simulations are based on the accrual, the peak value, and the option value methods. For each of these estimation methods, three simulation approaches are used. The three simulation methods are based on different uses of the age indicators. In every case the simulations are done by recalculating the relevant incentive (accrual, peak value, or option value) to correspond to the program change. (In addition to the incentive measure per say, the social security wealth measure and wage earnings are also recalculated to correspond to the change in the program.) Then the retirement rates are re-estimated using the new measures.

\begin{tabular}{|c|c|c|c|c|c|c|}
\hline \multirow{3}{*}{$\begin{array}{l}\text { Simulation } \\
\text { Method }\end{array}$} & \multicolumn{6}{|c|}{ Simulation and Estimation Method } \\
\hline & \multicolumn{3}{|c|}{$\begin{array}{c}\text { Three-Year Delay in } \\
\text { Eligibility Ages }\end{array}$} & \multicolumn{3}{|c|}{$\begin{array}{l}\text { "common reform" -- ER at } \\
60, \text { NR at } 65, \text { replacement } \\
\text { rate of } 60 \% \text { (of age } 59 \\
\text { earnings) at } 65,6 \% \\
\text { reduction before } 65,6 \% \\
\text { increase after } 65 .\end{array}$} \\
\hline & Accrual & $\begin{array}{l}\text { Peak } \\
\text { Value }\end{array}$ & $\begin{array}{l}\text { "Option } \\
\text { Value" }\end{array}$ & Accrual & $\begin{array}{l}\text { Peak } \\
\text { Value }\end{array}$ & $\begin{array}{l}\text { "Option } \\
\text { Value" }\end{array}$ \\
\hline $\begin{array}{l}\text { S1: Without age } \\
\text { indicators }\end{array}$ & $x$ & $x$ & $X(X)$ & $X$ & $x$ & $X(X)$ \\
\hline $\begin{array}{l}\text { S2: With age indicators } \\
\text { but don't increment age } \\
\text { effects }\end{array}$ & $X$ & $x$ & $x$ & $X$ & $x$ & $x$ \\
\hline $\begin{array}{l}\text { S3: With age indicators } \\
\text { and increment age } \\
\text { effects }\end{array}$ & $x$ & $x$ & $X(X)$ & $X$ & $x$ & $X(X)$ \\
\hline
\end{tabular}

The key feature that distinguishes the three methods is the use of age indicators. The first simulation method (S1) does not use age indicators at all, either in the estimation or in the simulation. Only a linear measure of age is used as a control variable. In this case only the incentive measures (and the related variables) are recalculated to simulate the effect of the reforms. The second simulation method (S2) uses age indicators in the estimation, but does not use the age indicators in the simulation. The third method (S3) uses age indicators in the estimation, and in addition 
uses adjusted age indicators to simulate retirement under the program changes.

Simulation method S2 likely minimizes the simulated effect of the program changes. The effect of the incentive measures is estimated conditional on the individual age indicators. But in predicting the effect of program changes, the simulations account only for the change in the incentive measures, and do not account for the age effects. This will clearly understate the true effect of the program changes assuming that there are important program eligibility-age effects.

Simulation method S3 may typically yield the largest simulated effect of the program changes. The estimated age indicator effects, as well as the program incentive effects, are used to predict the effect of the program changes. For example, for the three-year eligibility delay, the age indicator for a given age is taken to be the estimated age indicator three years prior to the given age. The age 60 indicator, for example, is taken to be the estimated age 57 indicator. The result is that under the three-year eligibility delay, the projected retirement rate at age 60 is approximately the same as the current program age 57 retirement rate. The spike at the early retirement age under the current program, for example, shows up three years later under the reform. This approach assumes that all of the estimated age effects can be attributed to the eligibility age program provisions. (The ages include the age at which persons are eligible for one or more programs, as well as the "normal" retirement age.)

Simulation method S1 perhaps provides a middle ground. In this case, the estimation method does not explicitly allow for increases in retirement at given eligibility ages and thus these effects are not allowed to influence the simulated effect of program changes. These effects will only be reflected in the simulations if they are captured by the estimated incentive effects. Recall that in our terminology, the incentive measures are the option value, the peak value, and the single year accrual financial measures; they do not include the eligibility age effects per se, which may also reflect additional incentives. Changing the early entitlement age by three years, for example, will change the incentive measures and SSW, at every age, and the effect of this change is captured by the $\mathrm{S} 1$ simulations. But any other eligibility-age effects, such as "social norms" or other reasons to retire at given eligibility ages such as liquidity constraints, are not captured by the S1 simulations.

As the simulation results reported below show, method S3 most often yields the largest estimated effect of program changes. But this is not always the case. In several instances, method S1 yields larger effects than method S3.

In this introduction, we discuss-in the next section--simulation results based on the option value (OV) estimation results and using the $S 1$ and the $S 3$ simulation methods, marked by the bold double "X(X)"s in the table. Without undo complexity, this allows us to describe the general features of the results and to direct attention to the most important issue in estimation and simulation, the use of age indicators. We also focus solely on the results for mem for expositional convenience, but results for women 
as well as men are presented in each country chapter.

\section{Simulation Results}

We begin by considering the results for the three-year delay in program eligibility. We first show results based on the third simulation method (S3). Then, for the threeyear delay simulation, we compare results based on the first (S1) and third (S3) simulation methods. Next we consider the predicted effects of the common reform. And then we compare results under the common reform and under the three-year eligibility delay. Before proceeding to cross-country comparisons, however, we briefly explain why country-to-country differences in simulated results should be expected.

\section{a. Differences Across Countries}

Although, overall, the simulated effects of the illustrative reforms are large in all countries, the magnitude of the effect differs from country to country. There are several reasons for the differences: The first, and the single most important reason, is that the current programs differ substantially among countries and thus the effect of given reforms should differ as well. A second reason is that the data files on which the estimates are based differ from country to country. In a few countries, the data pertain to only a portion of the workforce. A third reason is that there may be differences across countries in individual responses to a given incentive. A fourth reason, related to the second, is that the precise calculation of the incentive measures may differ somewhat from country to country. A fifth reason is that the precise implementation of the simulations may differ among the countries. It is of course not possible to apportion the quantitative effect of each of these reasons.

The models described above are used to predict the effect of program incentives (and other variables) on labor force departure rates-hazard rates, the likelihood that a person in the labor force at a given age will leave the labor force at that age. The simulations begin with base hazard rates, that is, the predicted hazard rates under the current program. Then new hazard rates are predicted based on the provisions of the illustrative reform. These hazard rates are then used to predict the proportion of persons out of the labor force at given ages, and these proportions are used to determine the proportion of person out of the labor force in given age ranges, such as 56 to 65 . Thus any of the reasons for differences that affect the base hazard rates (under the current program) or the predicted hazard rates under the illustrative reforms will lead to different results among the countries.

\section{b. Three-Year Delay in Eligibility}

Turning to cross-country comparisons, we begin with simulations of the effect of a three-year delay in eligibility. Results for men aged 56 to 65 on shown in Figure 13. The figure shows the out-of-the-labor (OLF) percent for the base case, and under the eligibility delay. The eligibility delay estimates are based on the S3 simulation method. 
In all countries there is a noticeable reduction in the proportion of men out of the labor force when the eligibility ages are increased by three years.

The comparison among countries may be confounded, however, by the wide variation across countries in the age at which retirement begins. Thus the change in the proportion out of the labor force may vary more among countries at younger ages than over the entire 56 to 65 age range. To help to standardize for this effect, we define the first age at which at least 25 percent of men are out of the labor force, which we call the " $25 \%$ age." Then we consider the five years beginning with the $25 \%$ age (" $25 \%$ age + 4 yrs").

The results for the $25 \%$ age +4 yrs age range are shown in Figure 14, in which the $25 \%$ age is shown at the top of the bars for the base case. The $25 \%$ age ranges from age 53 in Italy to age 62 in Spain and the United States. Within the $25 \%+4 y$ rs age range, the OLF proportion is currently (under the base case) between 40 and 50 percent in 10 of the 12 countries. Within this more standardized age range there is typically a greater reduction in the OLF percent--when eligibility is delayed-then for the 56 to 65 age range.

The percent reduction in the OLF proportion for the $25 \%$ age $+4 y$ rs age range is shown in Figure 15. The average reduction is 47 percent, with a range from 14 percent in Canada to 77 percent in Germany.

Figure 16 is a comparison of results under the $\mathrm{S} 1$ and $\mathrm{S} 3$ simulation methods. The figure shows reductions in the OLF proportion for the $25 \%$ age $+4 y$ rs age range. Recall that under the S1 method predictions are based on changes in the incentive measures alone, while under the S3 method age-specific indicators are used as well.

There are two notable features of this figure. The first is that overall the reductions are large under either method, and in many of the countries two methods yield quite similar results. The average reduction is 47 percent under the S3 method and 28 percent under the S1 method. Under the S3 method, the reduction is at least 34 percent in 11 of the 12 countries. Even using method $\mathrm{S} 1$, the reduction is greater than 23 percent in six of the twelve countries (and in two of these countries the reduction is greater under the $\mathrm{S} 1$ than under the $\mathrm{S} 3$ method). The reduction is between 12 and 18 percent in 4 countries. Only in Italy and Japan is the estimated effect under the S1 method quite small. For the first six countries-Spain, the Netherlands, France, Canada, Germany, and Denmark- the two methods yield "rather similar" results. In the first eight countries, the reduction under the $\mathrm{S} 1$ method is at least 47 percent of the reduction under the S3 method. Thus on balance, the reduction in the OLF proportion is large under either approach.

The second notable feature of the figure is the similarity across countries in the reduction under the S3 method. The reduction is between 34 and 55 percent in 9 of the 12 countries. (In Germany and Sweden, the reductions are 77 and 68 percent 
respectively.) This similarity reflects the similarity in the estimated age effects at program eligibility ages. In all countries there are similar "spikes" in the hazard rates at these program eligibility ages, such as those for the United States and Germany shown in Figures 6 and 8 above.

In summary: in almost every country, the estimates under either method show very large reductions in the OLF proportion when program eligibility ages are raised. The reductions, however, are typically larger under the S3 method, which allows agespecific variables to capture the effect of benefit eligibility on retirement. Based on the strong empirical regularity between retirement rates and program eligibility ages, as discussed above and in the first volume, we believe that the S3 method likely provides the more tenable predictions of the long-run reductions in the OLF proportions (although responses to increases in eligibility ages may not parallel responses to reduction in eligibility ages). But, even under the more restrictive $\mathrm{S} 1$ method-which does not directly allow for eligibility age effects--the predicted effect of the delay in eligibility ages is large in almost all countries.

\section{c. Common Reform}

We turn now to simulation results for the common reform. Recall that the common reform has three key features: (1) It sets the normal retirement age at 65. (2) It sets the early retirement age at 60 . (3) And, benefits are reduced actuarially if they are taken before age 65. (4) In addition, the replacement rate at the normal retirement age is set (approximately) at 60 percent of age 59 earnings. Figure 17 shows the OLF proportion for the 56 to 65 age range under the base case and under the common reform, based on the S3 method. Only in Germany and in the Netherlands is the OLF proportion reduced substantially. In 5 of the 12 countries, the common reform increases the OLF proportion. But there appears to be no clear pattern between the base proportion OLF and the reduction in the OLF proportion under the common reform. The variation in the OLF proportion, relative to the base, is reduced under the common reform, but substantial variation across countries remains.

For the $25 \%$ age $+4 \mathrm{yrs}$ age range, however, there is a strong pattern to the change in the OLF percent. The OLF proportion under the base and under the common reform for this age range is shown in Figure 18. In this figure, the countries are ordered by the $25 \%$ age. For the $25 \%$ age +4 yrs age range it is clear that the greatest reductions in the OLF proportion under the common reform are realized in the countries with the lowest 25 percent ages. The change in the OLF proportion in the $25 \%$ age + $4 y$ rs age range is shown in Figure 19. For the six countries with a $25 \%$ age less than 60 , the average reduction in the OLF proportion is 44 percent. For the six countries in which the $25 \%$ age is 60 or more, there is, on average, a 4 percent increase in the OLF proportion.

The systematic pattern of these results shows a strong correspondence with intuition. For the countries with the lowest $25 \%$ age, the common reform represents a 
substantial increase in the youngest eligibility age, and the actuarial reduction means that benefits at this age are much lower than under the base country plans. Thus, for these countries, the OLF proportion should decline under the reform, and that is the case for every country but Canada. But for the countries with a $25 \%$ age of 60 or greater the common reform may reduce the earliest eligibility age-as in the United States-and may provide a greater incentive to leave the labor force. In addition, the 60 percent replacement rate at the normal retirement age represents an increase for some countries, like the United States, and a reduction in the replacement rate for other countries. Consequently, in three of these six countries, there is an increase in the OLF proportion under the common reform simulation, and on average there is an increase in the OLF proportion. The seemingly anomalous result for Canada is explained by the fact that Canada is the only country in which the $25 \%$ age is below the nominal social security entitlement age; the $25 \%$ age is 58 while the social security entitlement age is 60 . In addition, Canada has relatively low benefits at the age 60 early retirement age. Thus the common reform significantly increases benefit levels, providing an additional inducement to retirement.

The simulated changes under the common reform based on the S1 and the S3 methods are compared in Figure 20. In each of the countries, both methods either predict a reduction in the OLF proportion, or both methods predict an increase in the OLF proportion. Overall, the magnitude of the simulated changes based on the two methods is rather similar as well. The most apparent exceptions are Italy, Canada, and Germany. Both methods, on average, show reductions in the OLF proportion in the six countries with the lowest $25 \%$ ages, and small changes in the OLF proportion for the six countries with the highest $25 \%$ ages. The differences between the groups are more muted, however, under the S1 method. Based on the S3 method, the average OLF change is -44 percent for the first 6 countries and +4 percent for the last six, as noted above. Based on the S1 method, the OLF change is -21 percent for the bottom six countries and -4 percent for the top six. Most of the difference between the methods is accounted for by the differences for Italy, Belgium, Germany, and Canada. (The anomalous result for Canada is explained above). Again, on balance the two methods suggest similar results. Like the simulated effects of the three-year eligibility delay, we believe that the S3 method is likely to give the most reliable long run predictions.

\section{d. Comparing the Three-Year Eligibility Delay and the Common Reform}

Finally, Figure 21 compares the results for the three-year eligibility delay with the common reform results. The figure is based on the S3 method. It shows the percent change from the base under the two reforms for the $25 \%$ age $+4 y$ rs age range, which is shown as the label on the common reform bars. Recall that the three-year delay reduces the proportion out of the labor force in all countries. The average reduction in the OLF proportion is 47 percent, and there is little difference by the $25 \%$ age $(-49$ percent for the six countries with the lowest $25 \%$ ages and -45 percent for the six countries with the highest $25 \%$ ages). 
The results under the common reform, however, should depend on the base program provisions. As shown in Figure 19, for the first six countries the average reduction in the OLF proportion is -44 percent and for the last six countries the average increase in +4 percent. In particular, under the common reform benefits are not available in any country until age 60 . For many countries, current benefits are available well before age 60 . (The $25 \%$ age helps to identify the early eligibility countries.) In most of these countries-Italy, the Netherlands, Belgium, France, Canada, and Germany-the delay in eligibility should tend to reduce the OLF percent. And this is the result in all of these countries, with the exception of Canada (for reasons noted above). In addition, the actuarial reduction in benefits if they are taken before the age 65 normal retirement age, should tend to reduce further the OLF percent in most of these countries. And, the common reform represents a reduction in the replacement rate in some of the countries. In other countries, such as Spain and the United States current benefits are not available until age 60 or later. In these countries the common reform could increase the OLF proportion.

Overall, the relative effects of the two reforms are plausible, lending credence to the estimation approach. Under the three-year eligibility delay, which should reduce retirement ages in all countries, there is a reduction in the OLF proportion in each countries, and in many countries the reduction is very large. But for the common reform, the effects should depend on country-specific program provisions, as the simulations show.

\section{CONCLUSIONS}

Our introduction to the first volume of the project concluded with a striking graph showing a strong relationship across countries between social security program incentives to retire and the proportion of older persons out of the labor force (Figure 4 above). The weight of the evidence, we judged, was that the relationship was largely causal. The strong response of retirement decisions to within-country changes in program provisions over time, and to different provision for different groups at a point in time (shown in Figures 6-12), also point to a casual relationship between program provisions and retirement.

The results of the country analyses reported in this volume confirm the strong causal affect of social security program retirement incentives on labor force particiaption. But perhaps more important, the results in this volume show the large magnitude of these effects. Across 12 countries with very different social security programs and labor market institutions, the results consistently show that program incentives accord strongly with retirement decisions. The magnitude of the estimated effects varies from country to country, but in all countries the effects are large.

The magnitude is illustrated most clearly by the simulations reported in each country paper, and we have emphasized the simulations in this introduction. 
Considering the average across all countries, a reform that delays benefit eligibility by three years would likely reduce the proportion of men 56 to 65 out of the labor force between 23 and 36 percent, perhaps closer to 36 percent in the long run. For the $25 \%$ + 3yrs age range, the average reduction would likely be between 28 to 47 percent, and perhaps closer to 47 percent in the long run. The effects are much larger than this in some countries and in virtually every country the effects are large regardless of the estimation method.

On the other hand, an illustrative "common reform"-- with early retirement at age 60 , normal retirement age 65 , and actuarial reduction in benefits between 65 and 60-has very disparate effects across the countries, depending on the provisions of the current program in each country. For the countries in which the current modal retirement age is younger than 60 , this reform typically implies a reduction in retirement incentives, and under this reform, the simulated proportion of older persons out of the labor force declines substantially in most countries. But for countries in which the modal retirement age is 60 or older, this reform may represent an increase in retirement incentives, and the proportion of persons out of the labor force increases, on average, in these countries. The strong correspondence between the simulation results and a priori expectations lends credence to the estimation procedures used in the country papers.

In short: the results in this volume provide an important complement to the first volume. The results leave no doubt that social security incentives have a strong effect on retirement decisions. And the estimates show that the effect is similar in countries with very different cultural histories, labor market institutions, and other social characteristics. While countries may different in many respects, the employees in all countries react similarly to social security retirement incentives. The simulated effects of illustrative reforms reported in the country papers make clear that changes in the provisions of social security programs would have very large effects on the labor force participation of older employees.

In the next stage of the project, we will use the estimation results and simulation methods developed in this stage to estimate the financial implications of changes in program provisions.

\section{APPENDIX}

\section{Incentive Measures}


In this appendix we review the relationship between the two forward-looking incentive measures-the option value and the peak value. Under the option value formulation, the value at age $t$ of retirement $r$ is given by

$$
V_{t}(r)=\sum_{s=t}^{r-1} \beta^{s-t} E_{t}\left(Y_{s}^{\gamma}\right)+\sum_{s=r}^{S} \beta^{s-t} E_{t}\left(k B_{s}(r)\right)^{\gamma}
$$

using the Stock-Wise specification. Here $Y$ is future wage income and $B$ is social security benefit income, which depends on the retirement age $r$. For simplicity, the probabilities of being alive to collect the income or the benefits have been suppressed. The gain from postponing retirement to $r$, versus retiring at age $t$, is given by

$$
V_{t}(r)=\sum_{s=t}^{r-1} \beta^{s-t} E_{t}\left(Y_{s}^{\gamma}\right)+\sum_{s=r}^{S} \beta^{s-t} E_{t}\left(k B_{s}(r)\right)^{\gamma}-\sum_{s=t}^{S} \beta^{s-t} E_{t}\left(k B_{s}(r)\right)^{\gamma}
$$

If $r^{*}$ is the retirement year that gives the maximum expected gain, the option value is given by

$$
\begin{aligned}
& O V_{t}\left(r^{*}\right)=\sum_{s=t}^{r-1} \beta^{s-t} E_{t}\left(Y_{s}^{\gamma}\right)+\left[\sum_{s=r^{*}}^{S} \beta^{s-t} E_{t}\left(k B_{s}\left(r^{*}\right)\right)^{\gamma}-\sum_{s=t}^{S} \beta^{s-t} E_{t}\left(k B_{s}(t)\right)^{\gamma}\right] \\
& =\left(\begin{array}{l}
\text { discounted utility } \\
\text { of future wage }
\end{array}\right)+\left[\left(\begin{array}{l}
\text { discounted utility } \\
\text { of benefits if } \\
\text { retire at } r^{*}
\end{array}\right)-\left(\begin{array}{l}
\text { discounted utility } \\
\text { of benefits if } \\
\text { retiree at } t
\end{array}\right)\right]
\end{aligned}
$$

Considering this equation, we can see that there are two ways to calculate the option value used in the analyses in this volume: One way is to use prior estimated values for the utility parameters $(, \$$, and $\mathrm{k}$. The second is to set assume a value for $\$$ and to set $(=k=1$.

\section{Multiple Pathways to Retirement and Combining Programs}

In the United States, the social security program is the principle public program route to retirement. Only a small fraction of older persons enter retirement through the disability program. In some European countries, however, there are several public programs that provide routes to retirement. The case in Germany is discussed in the 
text and illustrated in Figure 5. Thus in considering the incentive to retire, it is important to recognize that retirement incentives under several programs may matter. The key question is which program, or programs, a person could choose to enter. That is, which are available to a given person. Who could retire under the disability program, for example. In some instances, administrative provisions limit the universe of persons who might be eligible. In other instances, a large fraction of persons could be eligible, but which persons are eligible is unknown. Thus the incentives facing a given individual must be estimated probabilistically. What we would like to have is the probability that each person is eligible for each program. Suppose that the incentive measure under each possible program is calculated for each person for each age. Then for each age these probabilities could be used to obtain a "weighted" incentive measure, where the weights are the probabilities that the person is eligible for each program. This is essentially an "instrumental variable" approach.

In principle, eligibility probabilities should be estimated for each person for each age, depending on administrative rules as well as individual attributes. During the course of this part of the project, several different approaches were tried in various countries. Eligibility for disability is a good example. Based on administrative rules, it might be assumed that every person is eligible for disability beginning at some age. Or it might be assumed that eligibility probabilities correspond to actual empirical take-up rates by age and other variables. (Where the take-up rate is estimated based on personal attributes.) Here, it is implicitly assumed that the take-up rate for a person with attributes $\mathrm{X}$ represents, on average, the eligibility rate for persons with attributes $\mathrm{X}$. There is no correct way to do this without knowing eligibility for a sample of persons and then being about to predict eligibility. In few, if any, countries was this an option. Thus, for the purposes of the estimates in this volume, we have elected to assign weights based on empirical take-up rates. In this case the disability "eligibility" probability will typically increase with age for example. (Deviations from this method are noted in the individual country papers.)

To explain the procedure we use the situation in Denmark, which is likely the most complicated of the country situations. Here are the programs in Denmark, together with the eligibility age and information to determine elibibility: 


\begin{tabular}{|l|l|l|l|}
\hline \multicolumn{2}{|c|}{ Program } & Eligibility Age & \multicolumn{1}{c|}{$\begin{array}{c}\text { Determine Eligibility Based } \\
\text { On: }\end{array}$} \\
\hline PEW & Post-Employment Wage & 60 to 66 & $\begin{array}{l}\text { Age and insurance fund } \\
\text { information }\end{array}$ \\
\hline TBP & $\begin{array}{l}\text { Transitional Benefits } \\
\text { Program }\end{array}$ & $\begin{array}{l}55 \text { to } 59 \\
\text { unemployed } \\
50 \text { to } 59 \text { from } \\
1994 \text { to } 1996\end{array}$ & $\begin{array}{l}\text { Age and insurance fund and } \\
\text { unemployment info in two } \\
\text { years prior to age }\end{array}$ \\
\hline PEP & $\begin{array}{l}\text { Public Employees } \\
\text { Pension }\end{array}$ & 60 to 69 & $\begin{array}{l}\text { Employer pension } \\
\text { contributions over required } \\
\text { period }\end{array}$ \\
\hline SDP & $\begin{array}{l}\text { Social and Disability } \\
\text { Pension }\end{array}$ & 18 to 66 & $\begin{array}{l}\text { Probability: based on } \\
\text { observed participation rates by } \\
\text { age-year-gender in each of } \\
\text { the three levels of the disability } \\
\text { program }\end{array}$ \\
\hline OAP & Old Age Pensions & 67 & Age $=67$ \\
\hline
\end{tabular}

An important calculation is the probability that a person is eligible for SDP. To obtain the probability of SDP eligibility, the approach is to use actual take-up rates by ageyear-sex cells, by disability level.

Suppose the calculation pertains to pension wealth SSW. The goal is to obtain a weighted measure based on the probability a person is eligible for a specific program at a given age. At 67 and beyond a person is only eligible for the OAP, and possibly the PEP. Persons who retire under other programs convert to OAP and start receiving benefits under that program at age 67 . Before age 67 , a person could be eligible for the PEW or the TBP, but not both. Assume we know for sure whether a person is eligible for these programs. These are the potential sources of wealth:

$\mathrm{SSW}_{\mathrm{OAP}}$ which is available to all persons

SSW $_{\text {PEW }}$ which could be available between 60 and 66

$\mathrm{SSW}_{\text {TBP }}$ which could be available between 55 and 59 or 50 and 59

$\mathrm{SSW}_{\mathrm{PEP}}$ which is available to public employees who meet certain criteria

SSW $_{\text {SDP }}$ which could be available even before age 50 


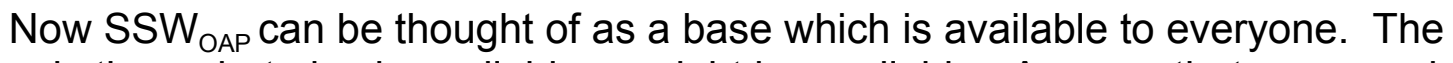
question is then what else is available or might be available. Assume that a person is not eligible for either PEW or TBP (or PEP), but that the person is eligible for SDP with probability $p$. Then the weighted average SSW would be

$$
S S W=S S W_{O A P}+p^{*} \max \left[0,\left(S S W_{S D P}-S S W_{O A P}\right)\right] .
$$

That is, with probability $p$ the person has more than $S_{S W}$ OAP . (Or, with probability $p$ the person would have SSW $W_{S D P}$ and with probability 1-p the person would have SSW ${ }_{\text {OAP }}$ only). The formula as set out above accounts for the (unlikely) possibility that SSW $\mathrm{SDP}_{\text {in }}$ lower than $\mathrm{SSW}_{\mathrm{OAP}}$, in which case the disability option would be ignored. $\left(\mathrm{SSW}_{\mathrm{SDP}}\right.$ can be collected beginning at an age much younger than 67 , so will almost surely be greater than $S_{S W}$ OAP , which can only be received beginning at age 67.)

After age 60, a person could be eligible for PEW, for example. (If you retire before you are eligible for this program you never get these benefits.) In that case, SSW is

$$
S S W=\max \left(S S W_{O A P}, S S W_{P E W}\right)+p^{*} \max \left[0,\left(S S W_{S D P}-\max \left(S S W_{O A P}, S S W_{P E W}\right)\right]\right.
$$

That is, the certain amount in this case is $\max \left(\mathrm{SSW}_{\mathrm{OAP}}, \mathrm{SSW}_{\mathrm{PEW}}\right)$. Once again, the maximum will almost surely be $S_{S W}$ PEW , since the person can take benefits $S_{S W}$ PEW, which incorporates benefits $S S W_{\text {OAP }}$ beginning at age 67 . And, with probability $p$ the person could be eligible for more, assuming that SDP would provide more.

A similar procedure is used to estimate social security wealth in two consecutive years. And from social security wealth in these two years, the social security accrual from one year to the next can be calculated. The peak value and option value measures are obtained in a similar fashion, but in these cases, wealth measures must be calculated for all ages into the future. 


\section{REFERENCES}

Coile, Courtney and Jonathon Gruber. "Social Security Incentives for Retirement," in David Wise, ed., Themes in the Economics of Aging. Chicago, University of Chicago Press, p. 311-341, 2000a.

Coile, Courtney and Jonathon Gruber."Social Security and Retirement," NBER Working Paper \#7830, August 2000b

Gruber, Jonathon and David A. Wise. "Social Security and Retirement Around the World: Introduction and Summary," in Jonathon. Gruber and David A. Wise, eds., Social Security and Retirement Around the World, University of Chicago Press, 1999a. Also published in Research in Labor Economics, Volume 18, JAl Press Inc, 1999.

Gruber, Jonathon and David A. Wise (eds.). Social Security and Retirement Around the World. University of Chicago Press, 1999b.

Kotlikoff, Laurence J. and David A. Wise. "Labor Compensation and the Structure of Private Pension Plans: Evidence for Contractual Versus Spot Labor Markets." in David A. Wise (ed.) Pensions, Labor, and Individual Choice, University of Chicago Press, 1985.

Kotlikoff, Laurence J. and David A. Wise. The Wage Carrot and the Pension Stick. W.E. Upjohn Institute for Employment Research, 1989.

Lazear, Edward. "Pensions as Severance Pay." in Zvi. Bodie and John Shoven (eds.), Financial Aspects of the United States Pension System, University of Chicago Press, 1983.

Stock, James H. and David A. Wise. "Pensions, the Option Value of Work, and Retirement," Econometrica, 58, 5, 1990: 1151-1180.

Stock, James $\mathrm{H}$. and David A. Wise. "The Pension Inducement to Retire: An Option Value Analysis," in David A. Wise (ed.), Issues in the Economics of Aging, University of Chicago Press, 1990: 205-224. 







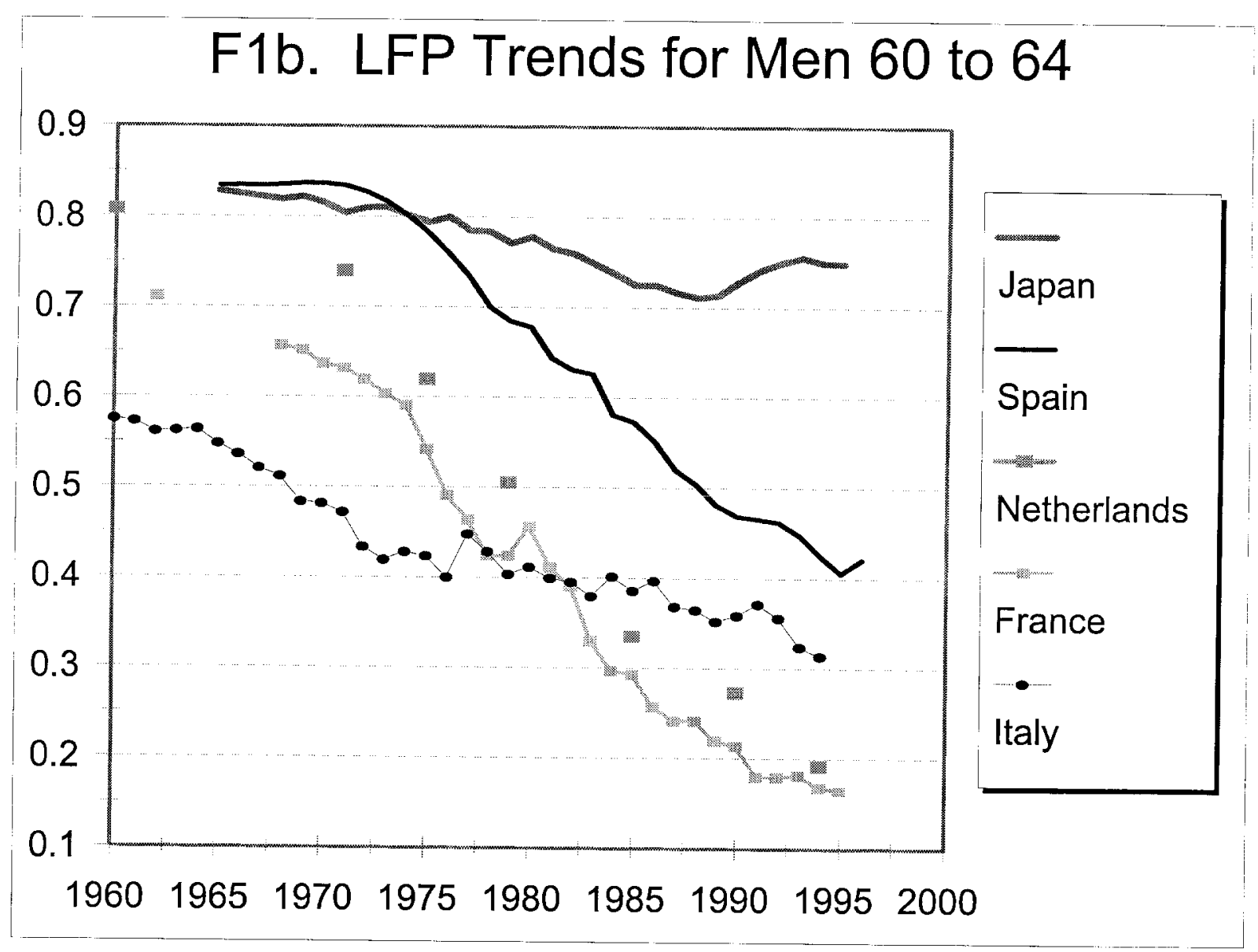


F2. Unused productive capacity

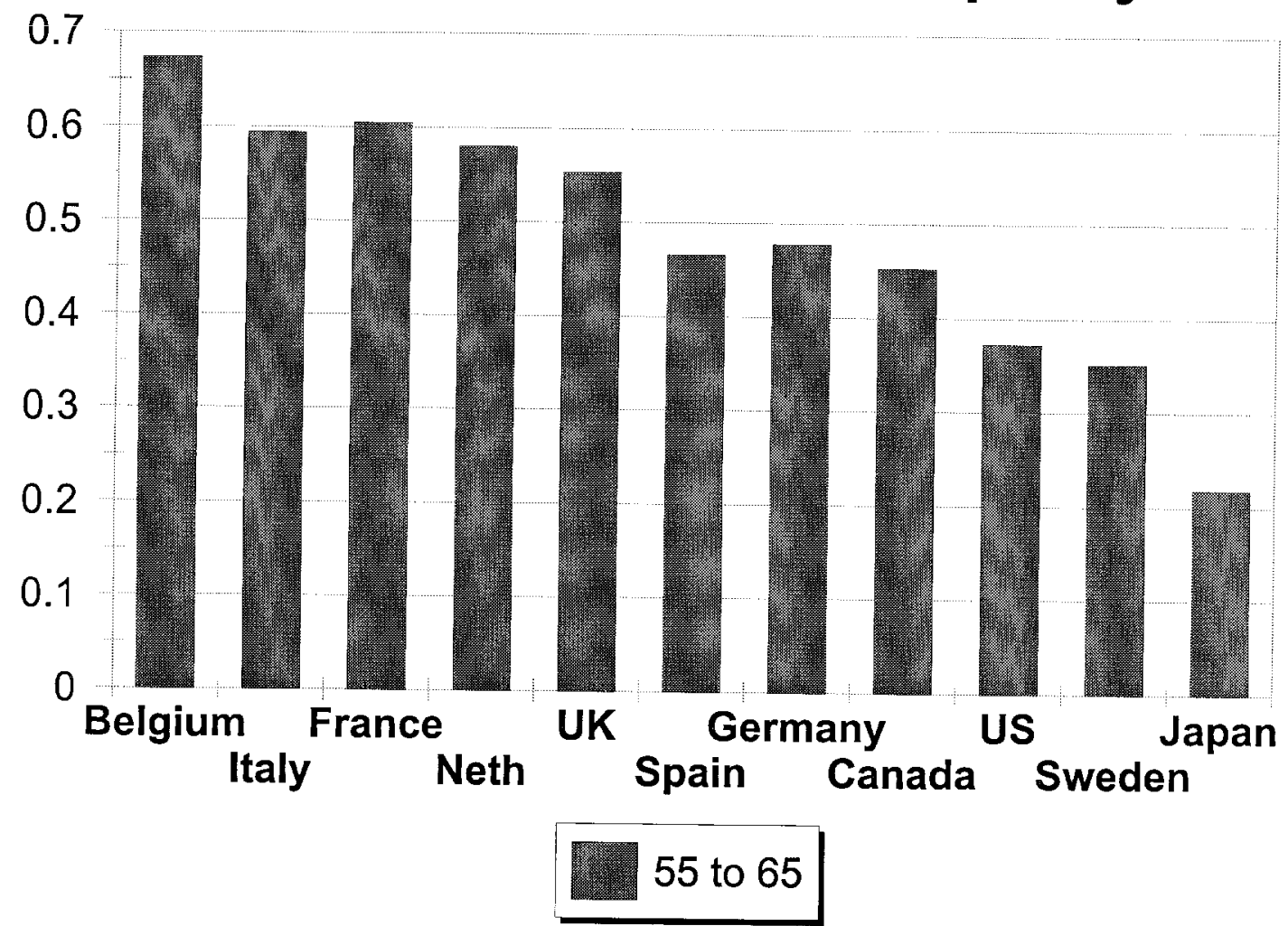




\section{F3. Sum of Tax Rates on Work}

From Early Retirement Age to 69




F4. Unused Capacity v Tax Force

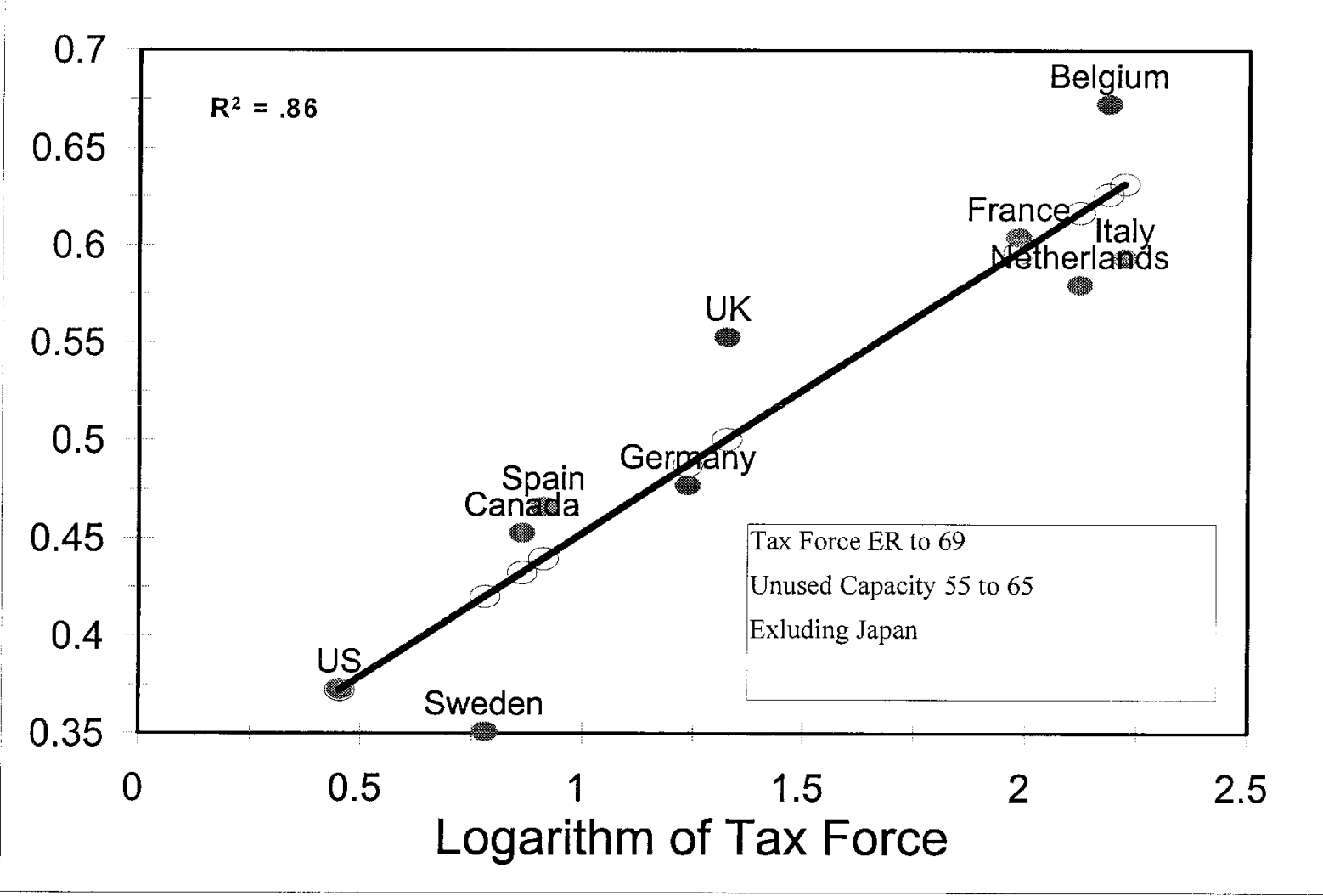




\section{F5. Germany: Pathways to Retirement For Men 1960 to 1995}

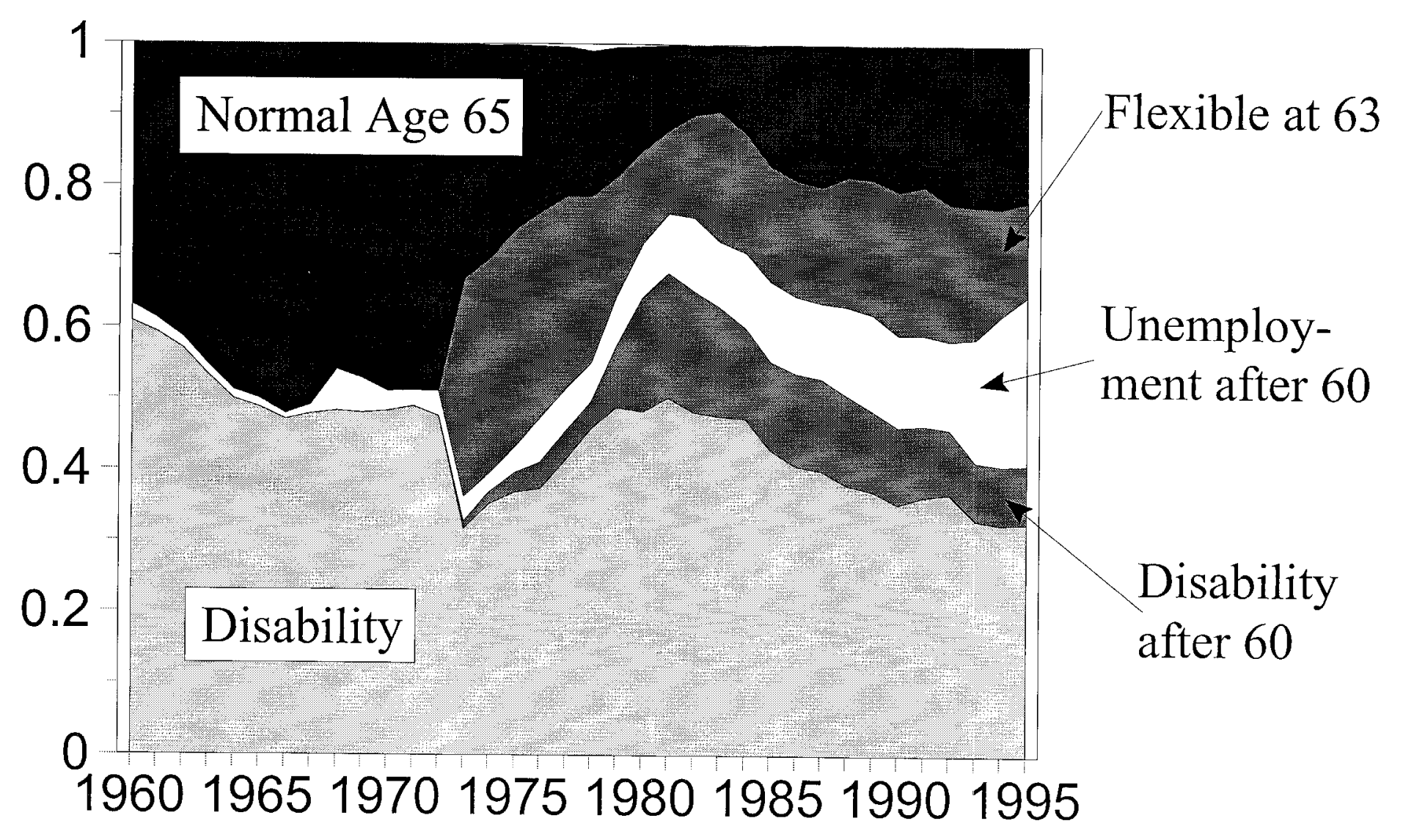

Source: Boersch-Supan 







\section{Fig 7. US Retirement Hazards for Men Social Security Only and Employer DB}

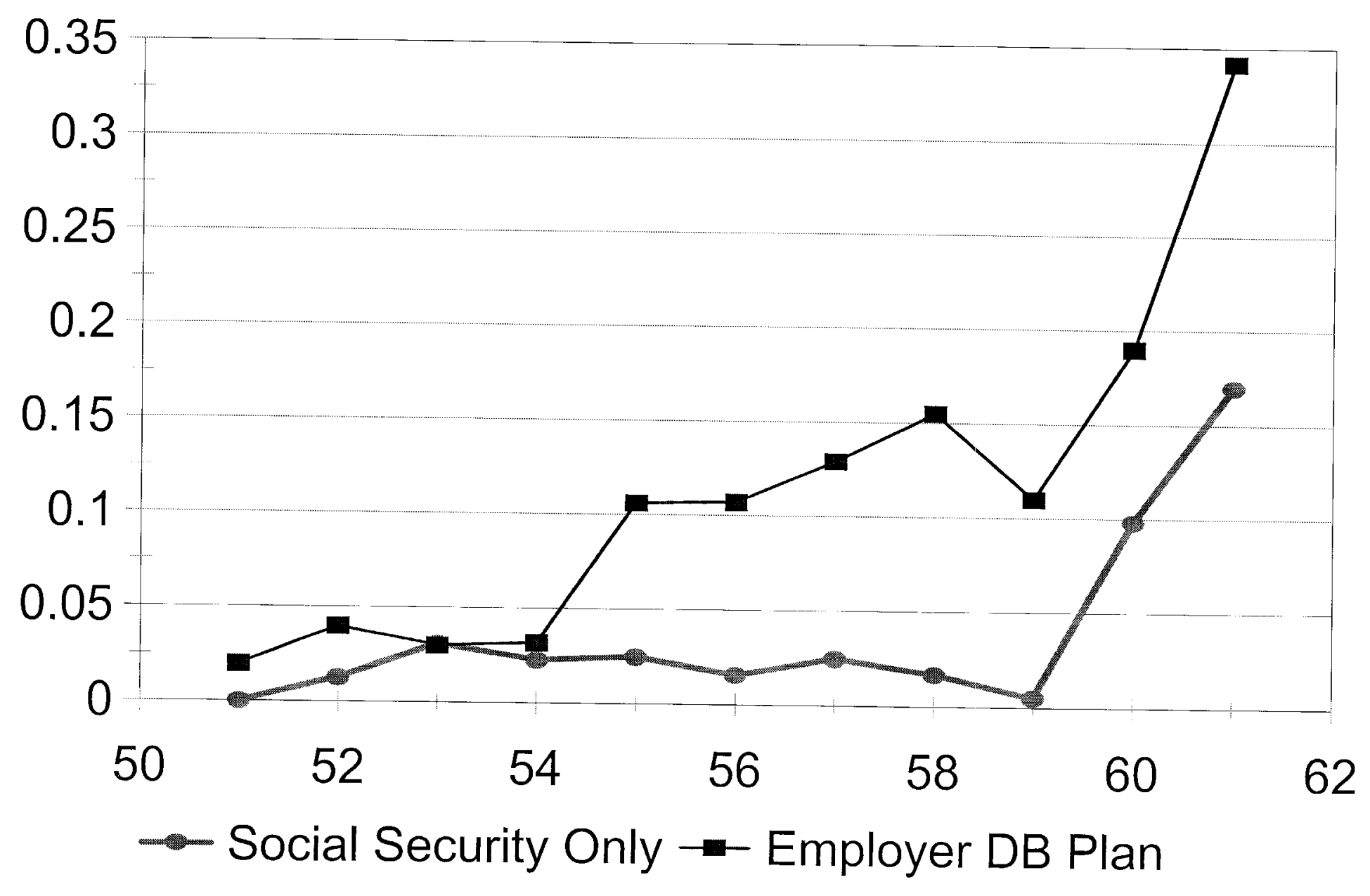




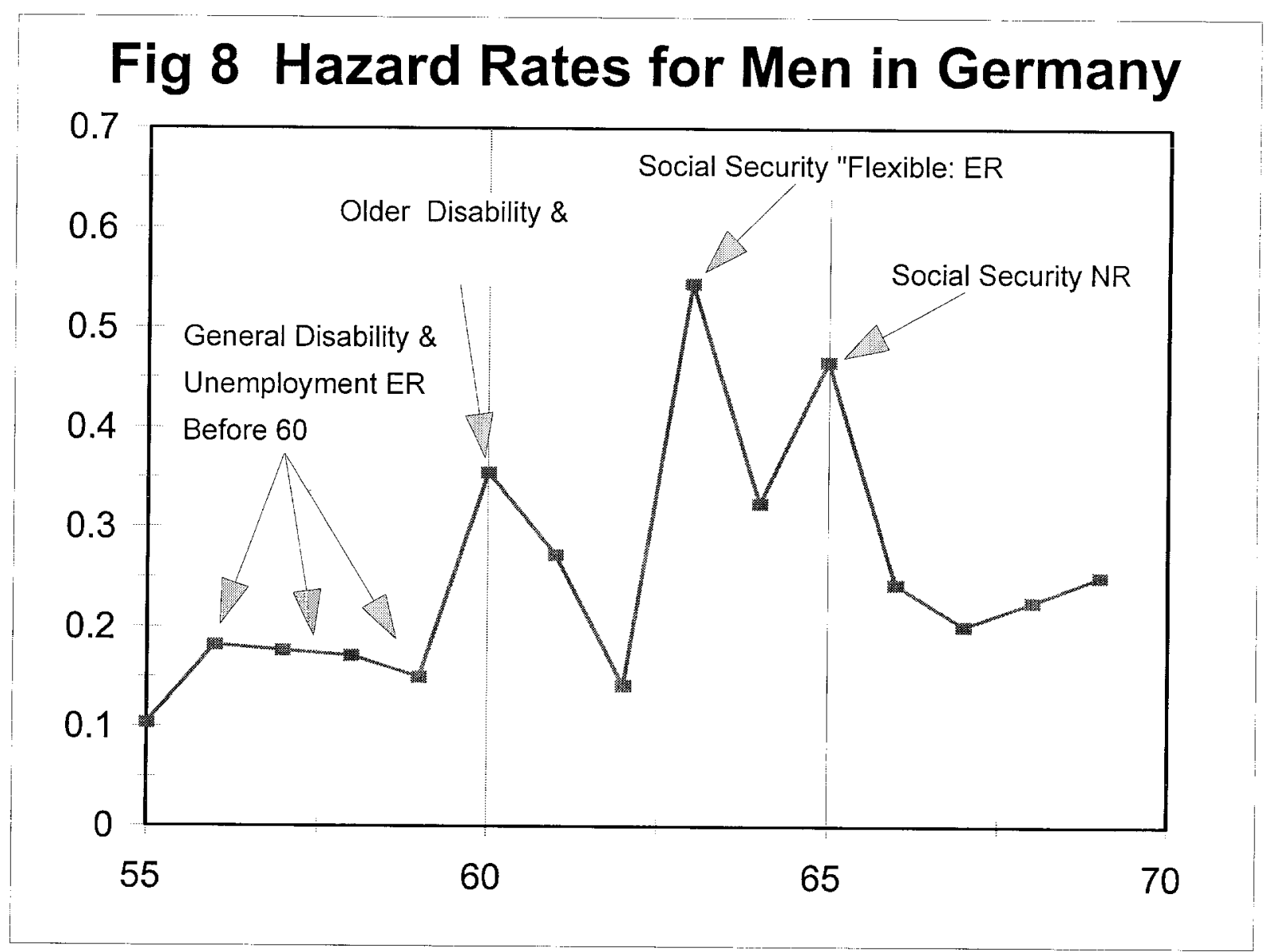




\section{Fig 9. Germany: Retirement Ages} Ages Before and After 1973 Reform

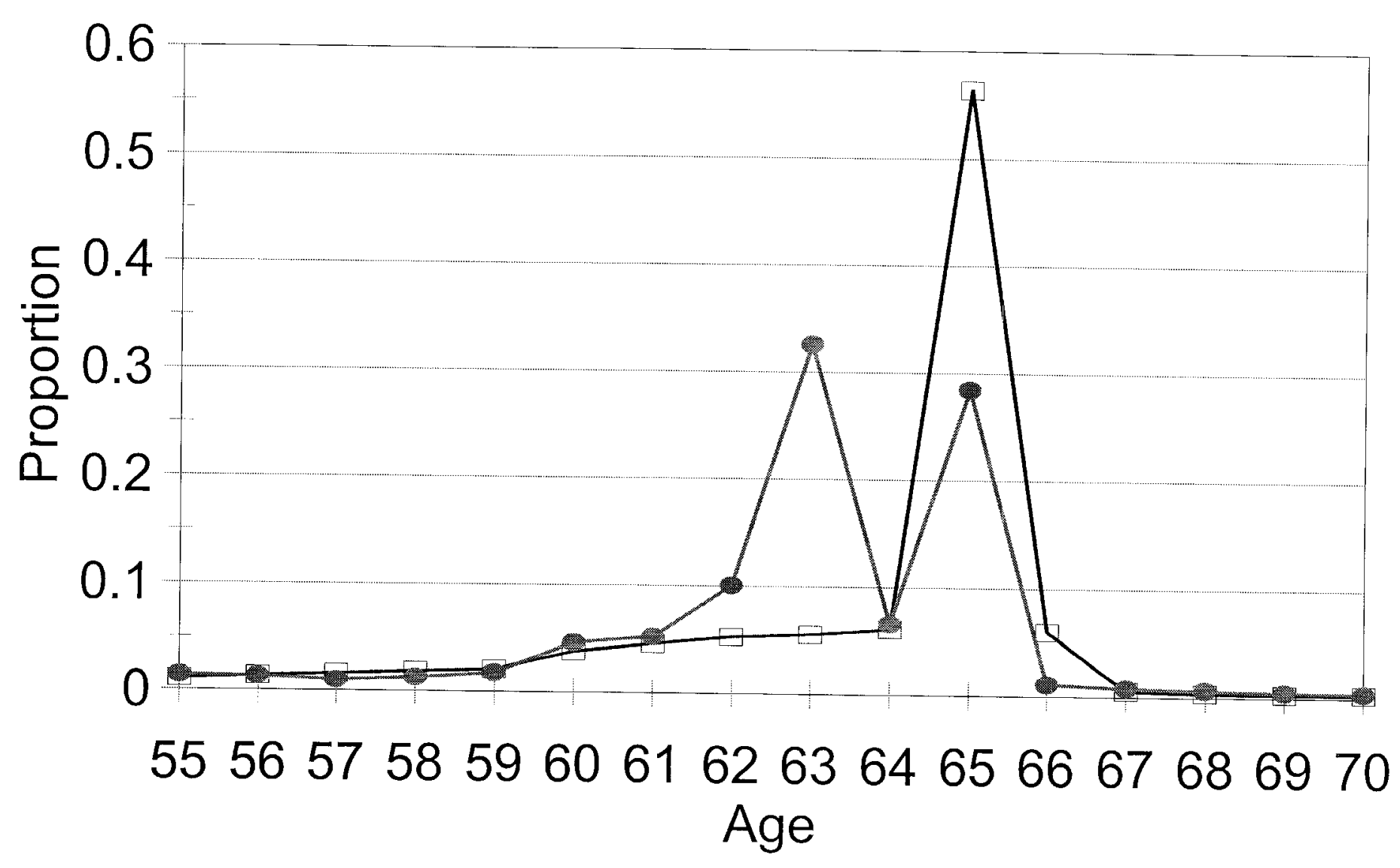

Source: Boersch-Supan

$$
\square 1970-1976
$$




\section{Fig 10. Germany: Retirement Ages}

Ages 1973, 1976, and 1980

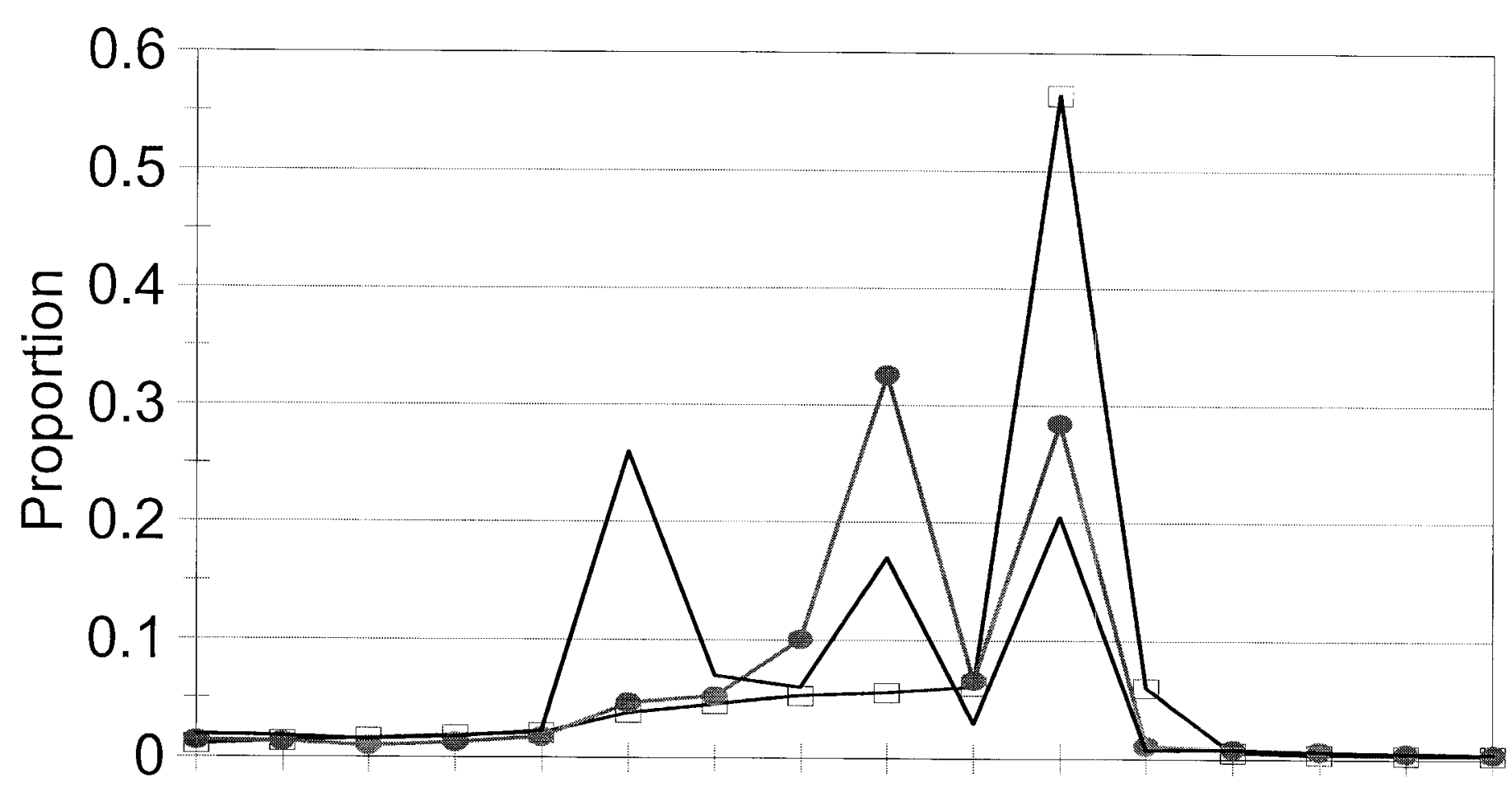

55565758596061626364656667686970 Age

Source: Boersch-Supan $\square 1970-1976-1980$ 


\section{Fig 11. Germany: Retirement Ages}

\section{For Men and Women in 1995}



Source: Boersch-Supan

- Men $\quad \rightarrow$-Womem 
Fig 12. UK Survival Rates for Men and Women

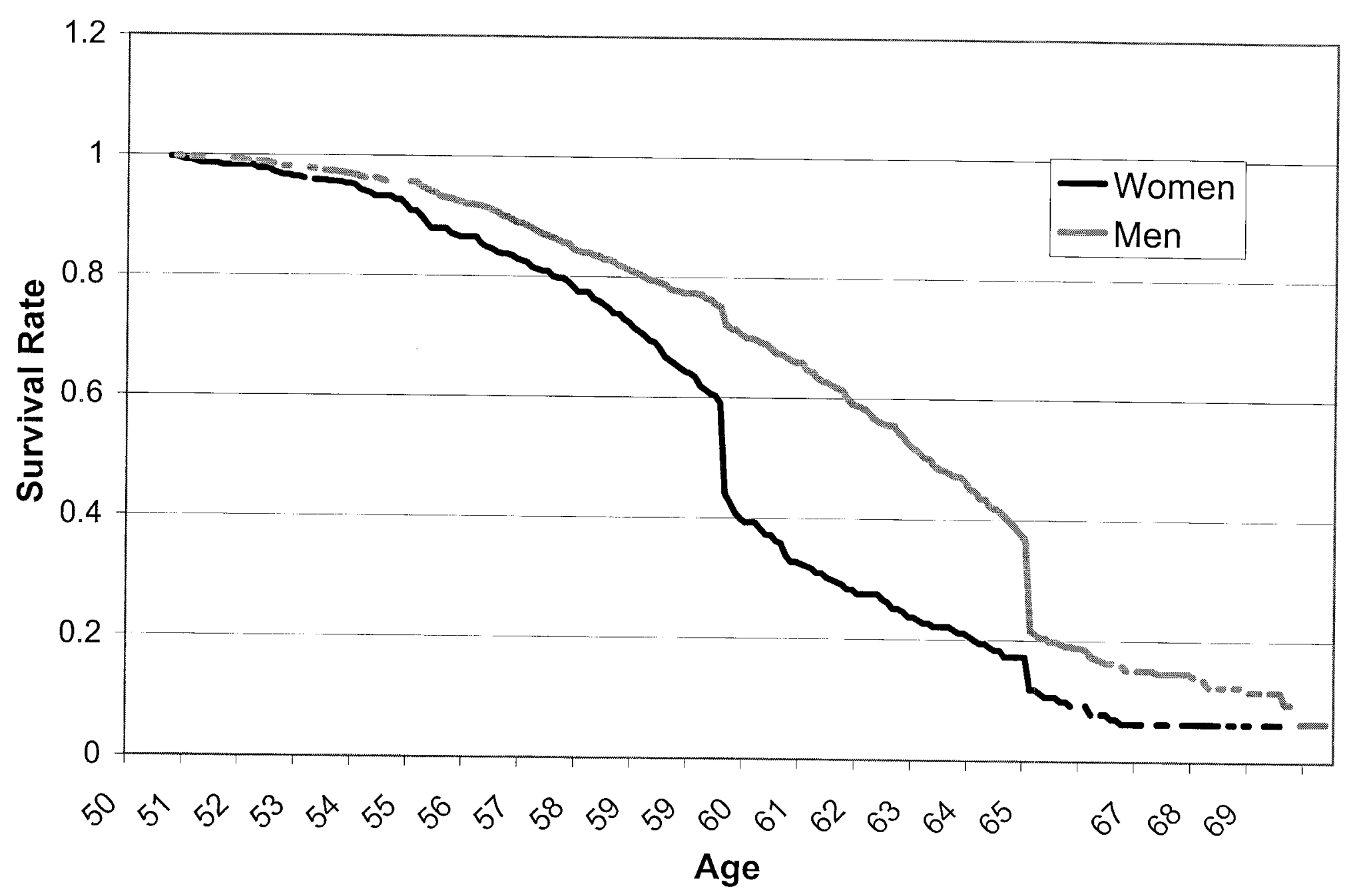




\section{F13. OLF Age 56-65 Base vs 3-Year Delay: OV-S3}

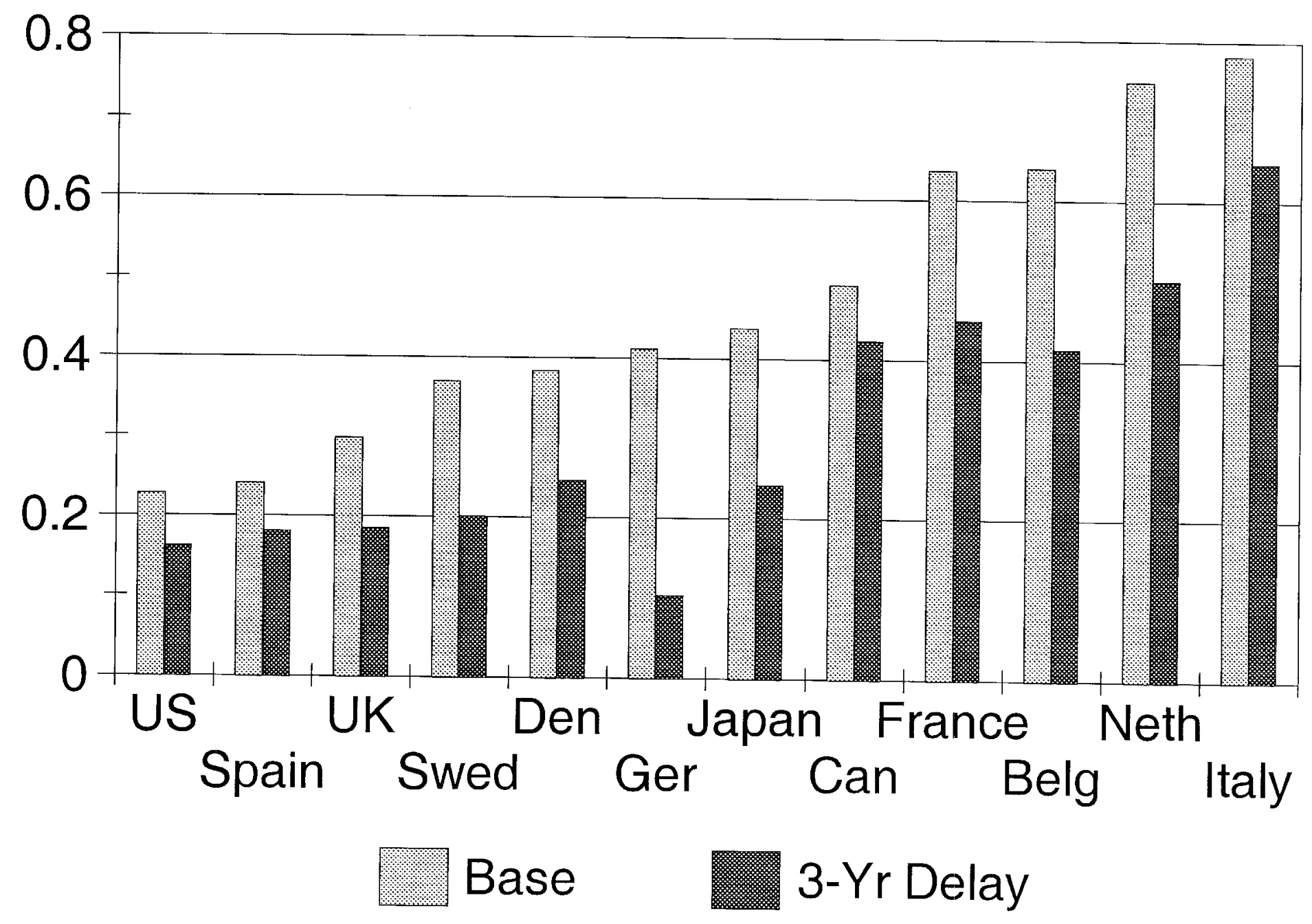




\section{F14. OLF 25\% Age + 4 Yrs \\ Base versus 3-Year Delay: OV-S3}

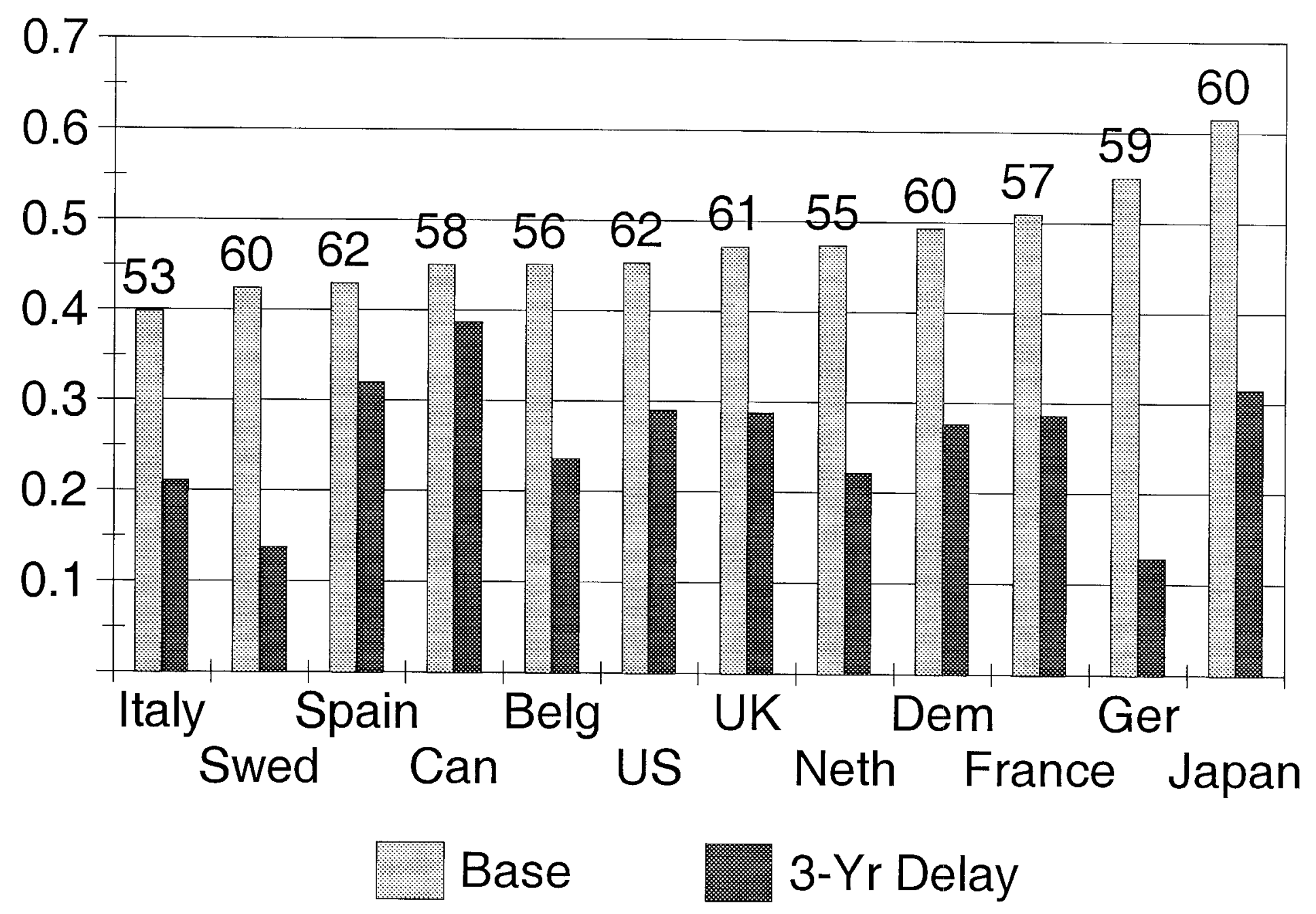









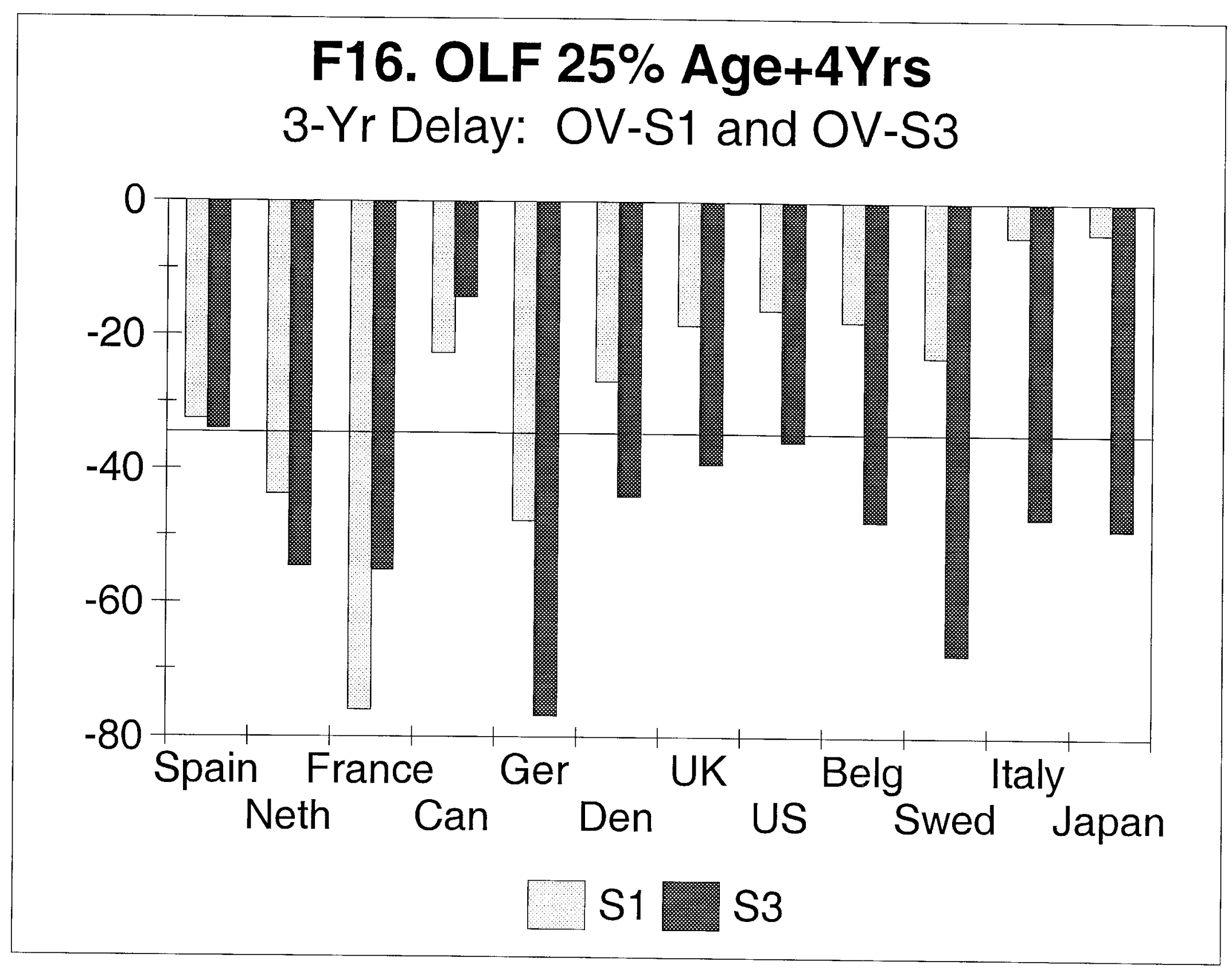




\section{F17. OLF Age 56-65 Base vs Common Reform: OV-S3}






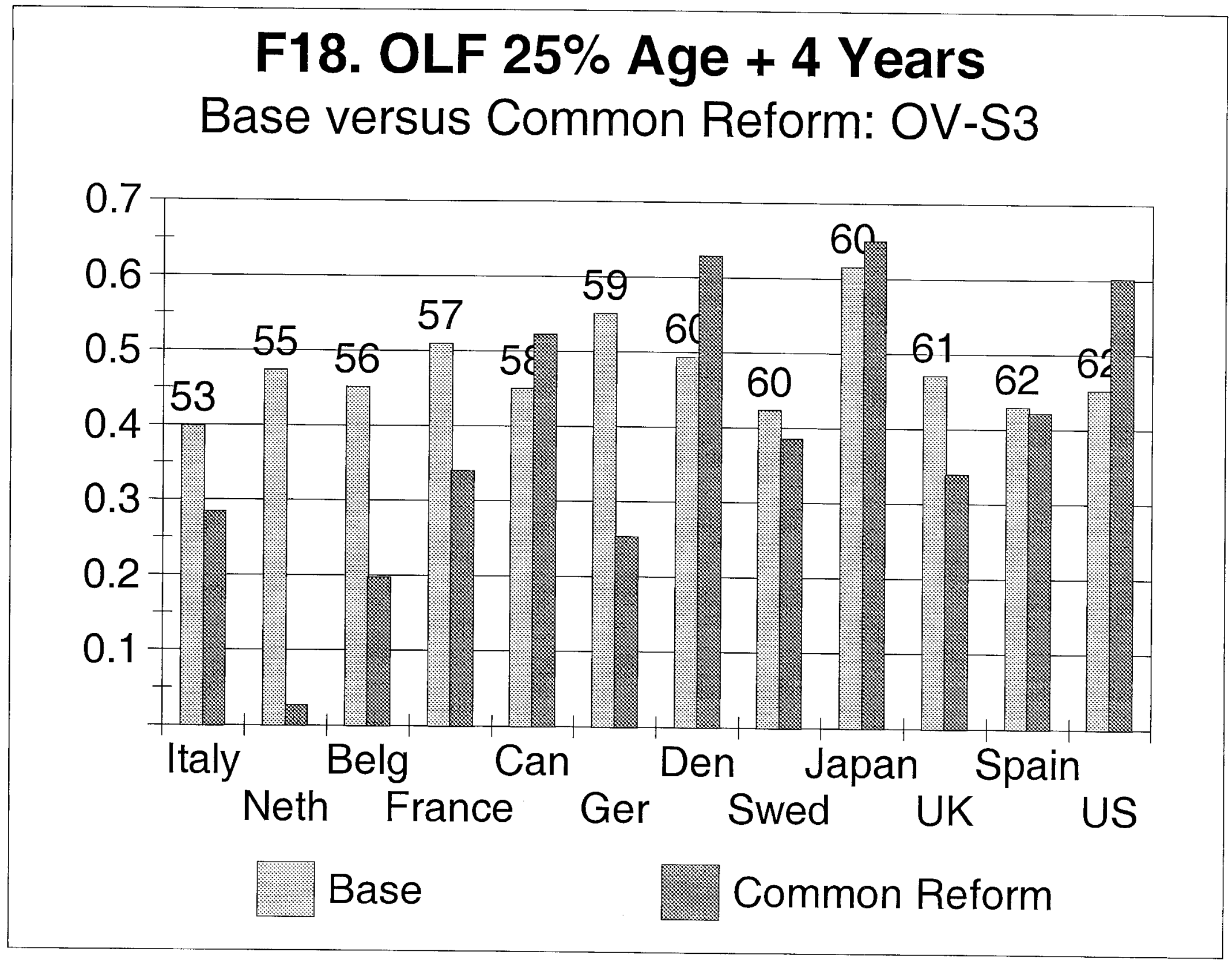




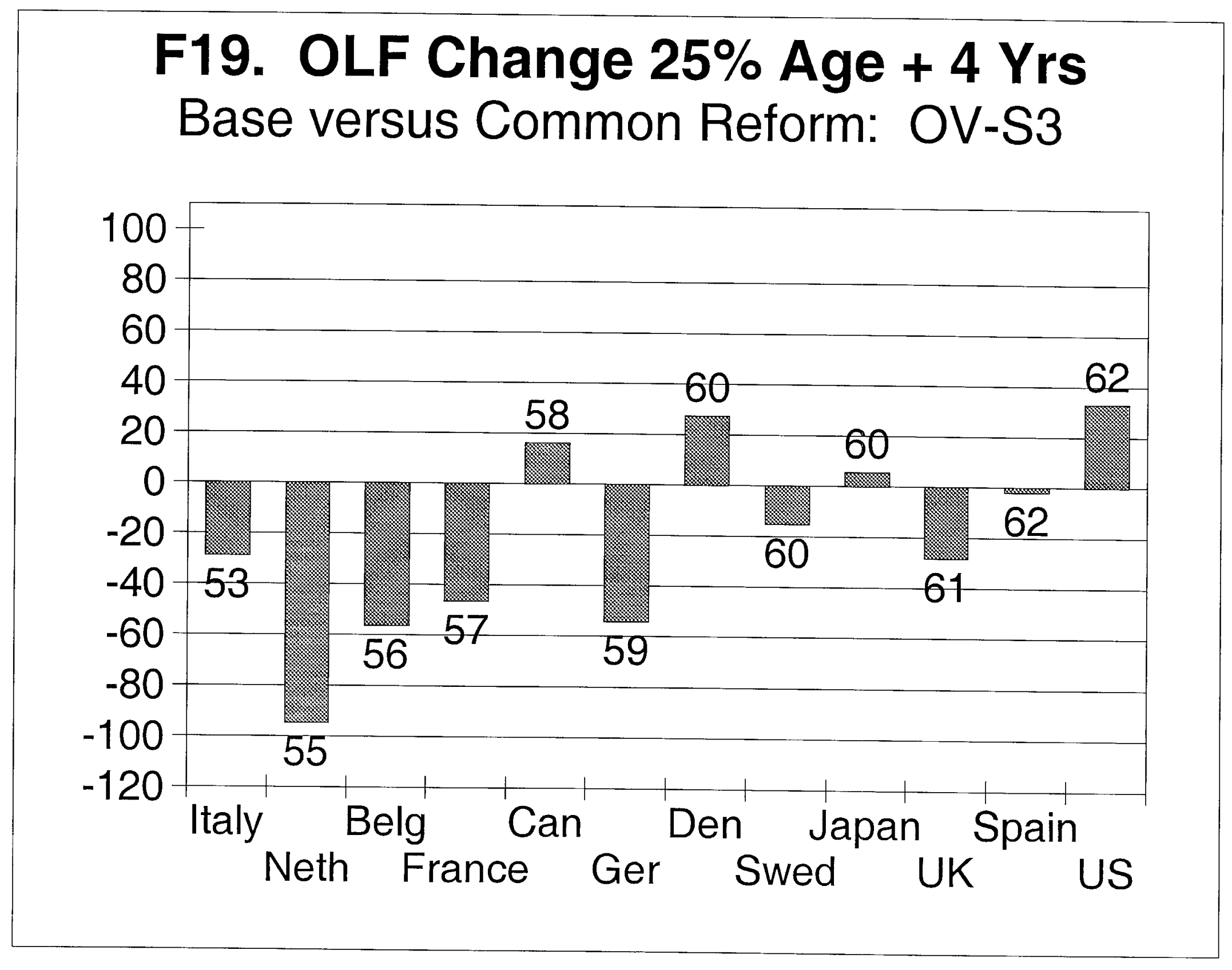




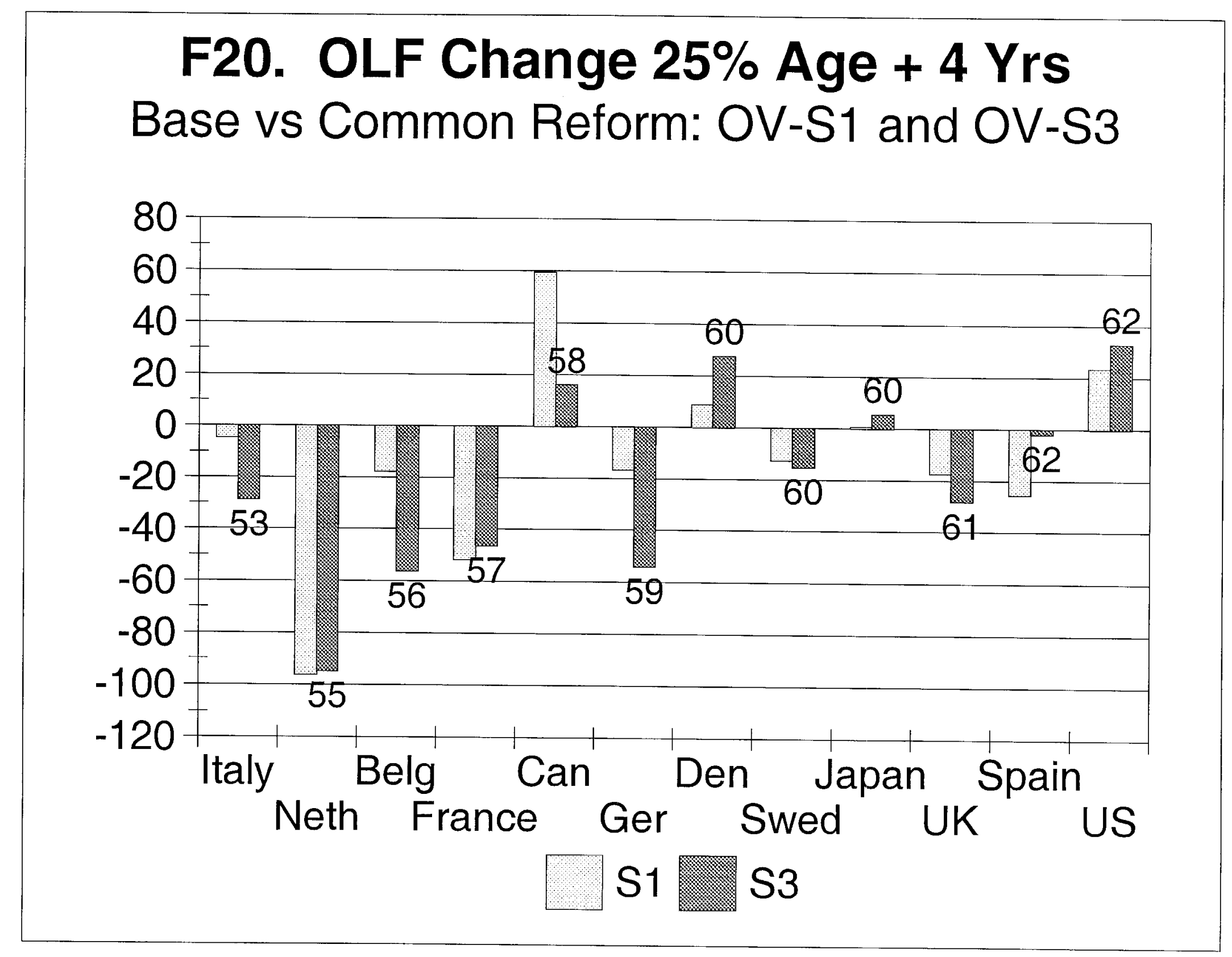




\section{F21. OLF Change 25\% Age + 4 Yrs 3-Year vs Common Reform: OV-S3}

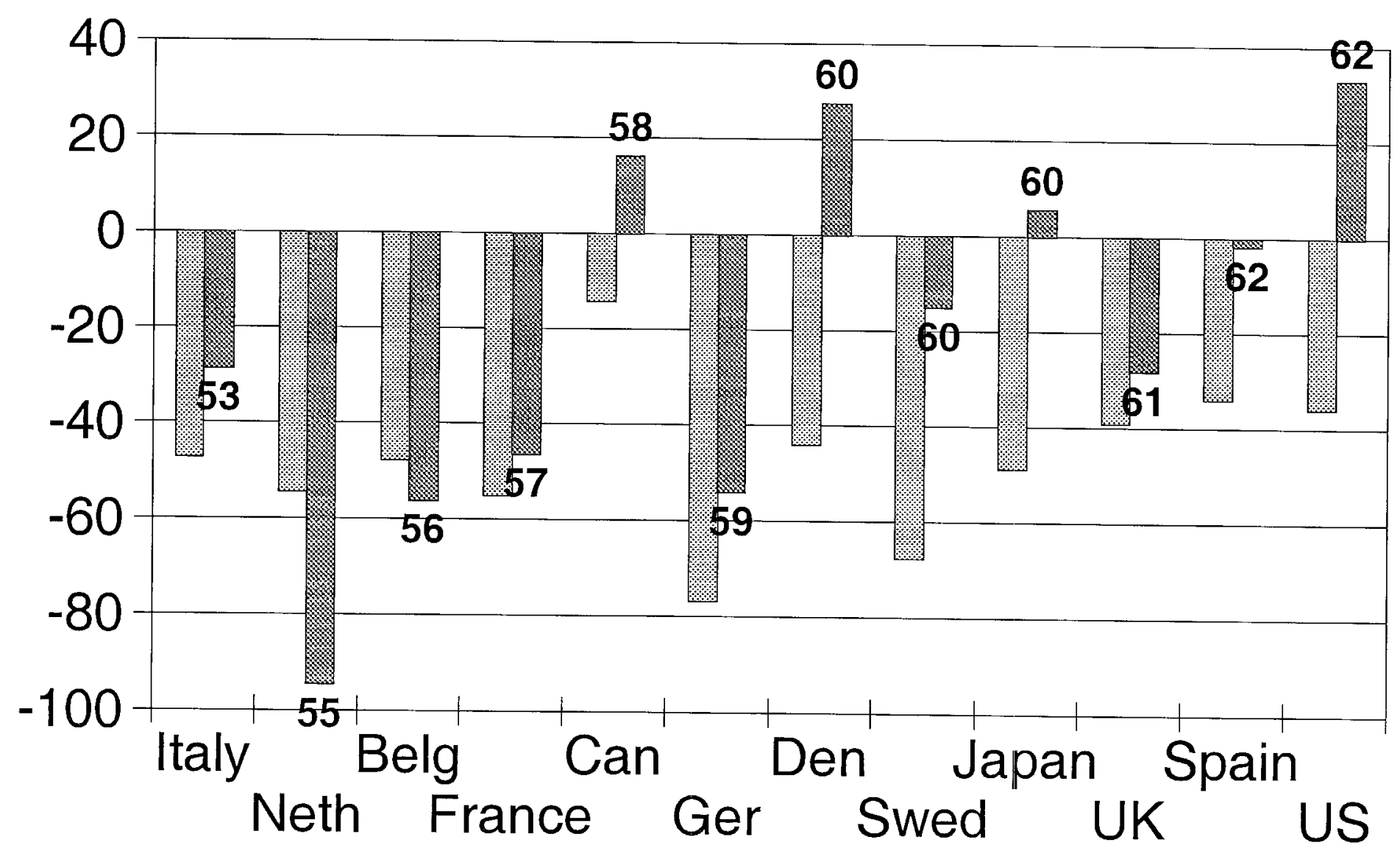

\section{Three-Year Delay Common Reform}

